\title{
Discrimination of MSA-P and MSA-C by RT- QulC analysis of olfactory mucosa: the first assessment of assay reproducibility between two specialized laboratories
}

Connor Bargar ${ }^{1 \dagger}$, Chiara Maria Giulia De Luca ${ }^{2,3+}$, Grazia Devigili ${ }^{4 \dagger}$, Antonio Emanuele Elia ${ }^{4}$, Roberto Cilia ${ }^{4}$, Sara Maria Portaleone ${ }^{5}$, Wen Wang ${ }^{1}$, Irene Tramacere ${ }^{6}$, Edoardo Bistaffa ${ }^{2}$, Federico Angelo Cazzaniga ${ }^{2}$, Giovanni Felisati ${ }^{5}$, Giuseppe Legname ${ }^{3}$, Alessio Di Fonzo ${ }^{7}$, Rong X ${ }^{8}{ }^{8}$, Steven Alexander Gunzler ${ }^{9,10}$, Giorgio Giaccone ${ }^{2}$, Roberto Eleopra ${ }^{4}$, Shu Guang Chen ${ }^{1,9^{*}}$ and Fabio Moda ${ }^{2^{*}}$ (D)

\begin{abstract}
Background: Detection of the pathological and disease-associated alpha-synuclein ( $a \mathrm{Syn}^{\mathrm{D}}{ }^{\mathrm{C}}$ ) in the brain is required to formulate the definitive diagnosis of multiple system atrophy (MSA) and Parkinson's disease (PD). We recently showed that $a S y n^{D}$ can be detected in the olfactory mucosa (OM) of MSA and PD patients. For this reason, we have performed the first interlaboratory study based on a-synuclein Real-Time Quaking-Induced Conversion (aSyn_ RT-QuIC) analysis of OM samples collected from PD and MSA patients with the parkinsonian (MSA-P) and cerebellar (MSA-C) phenotypes.

Methods: OM samples were prospectively collected from patients with a probable diagnosis of MSA-P ( $n=20$, mean disease duration 4.4 years), MSA-C ( $n=10$, mean disease duration 4 years), PD ( $n=13$, mean disease duration 8 years), and healthy control subjects (HS) $(n=11)$. Each sample was analyzed by aSyn_RT-QulC in two independent specialized laboratories, one located in Italy (ITA-lab) and one located in the USA (USA-lab). Both laboratories have developed and used harmonized aSyn_RT-QulC analytical procedures. Results were correlated with demographic and clinical data.
\end{abstract}

\footnotetext{
* Correspondence: sxc59@case.edu; fabio.moda@istituto-besta.it

+Connor Bargar, Chiara Maria Giulia De Luca and Grazia Devigili contributed equally to this work.

'Department of Pathology, Case Western Reserve University School of Medicine, Cleveland, $\mathrm{OH}$, USA

${ }^{2}$ Unit of Neurology 5 and Neuropathology, Fondazione IRCCS Istituto Neurologico Carlo Besta, Milan, Italy

Full list of author information is available at the end of the article
}

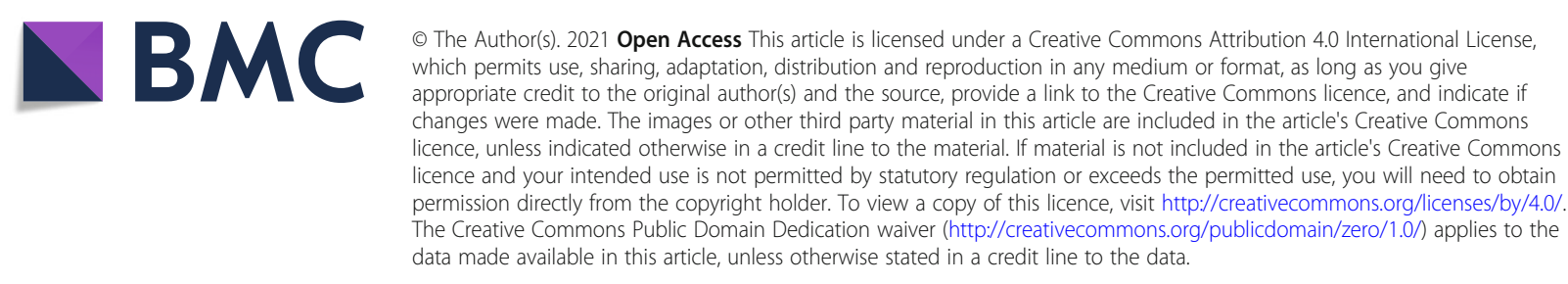


Results: The aSyn_RT-QuIC analysis reached a 96\% interrater agreement of results (IAR) between laboratories (Kappa $=0.93,95 \% \mathrm{Cl} 0.83-1.00)$. In particular, aSyn_RT-QulC seeding activity was found in the OM of 9/13 patients with PD (sensitivity 69\%, IAR 100\%) and 18/20 patients with MSA-P (sensitivity 90\%, IAR 100\%). Interestingly, samples collected from patients with MSA-C did not induce aSyn_RT-QulC seeding activity, except for one subject in USAlab. Therefore, we found that MSA-P and MSA-C induced opposite effects. Regardless of disease diagnosis, the aSyn_RT-QulC seeding activity correlated with some clinical parameters, including the rigidity and postural instability.

Conclusions: Our study provides evidence that $\mathrm{OM}-\mathrm{aSyn}{ }^{\mathrm{D}}$ may serve as a novel biomarker for accurate clinical diagnoses of PD, MSA-P, and MSA-C. Moreover, aSyn_RT-QulC represents a reliable assay that can distinguish patients with MSA-P from those with MSA-C, and may lead to significant advancements in patients stratification and selection for emerging pharmacological treatments and clinical trials.

Keywords: Alpha-synuclein, Olfactory mucosa, Real-Time Quaking-Induced Conversion, Misfolding, Biomarkers

\section{Background}

Multiple system atrophy (MSA) is a rare and rapidly progressing neurodegenerative disorder that can be classified into at least two main subtypes: the parkinsonian (MSA-P) and the cerebellar (MSA-C) types [1]. MSA-P shows prominent parkinsonism, such as tremors and postural instability, while MSA-C shows cerebellar ataxia $[2,3]$. Diagnosis of MSA is challenging because the clinical presentation often overlaps with that of other $\alpha$ synucleinopathies, including Parkinson's disease (PD), especially at the early stages. Nonetheless, MSA patients may display cruciform hypo-intensity in the pons (hot cross bun) and hyperintensity in the dorsal margin of the putamen (putaminal slit) by magnetic resonance imaging (MRI), as well as normal cardiac uptake of I-123 MIBG and normal olfactory function. In contrast, these two latter aspects are often impaired in PD patients [46]. Although these tests allow clinical diagnosis of MSA, about 20 to $40 \%$ of patients are still misdiagnosed, therefore better disease biomarkers are urgently needed [7].

A definitive diagnosis of $\alpha$-synucleinopathies relies on the detection in the brain of protein aggregates made of misfolded and disease-associated alpha-synuclein $\left(\alpha \operatorname{Syn}^{\mathrm{D}}\right)[8,9]$. Notably, the neuroanatomical distribution and morphological and biochemical features of $\alpha \operatorname{Syn}^{\mathrm{D}}$ aggregates differ between MSA and PD, and the reasons for this variability seem to be enciphered in the structure of $\alpha \operatorname{Syn}^{\mathrm{D}}{ }^{\mathrm{N}}$ that gives rise to distinct strains $[7,10,11]$. Thanks to the advent of the Real-Time QuakingInduced Conversion (RT-QuIC) assay, traces of $\alpha \operatorname{Syn}^{\mathrm{D}}$ were detectable in cerebrospinal fluid (CSF), olfactory mucosa $(\mathrm{OM})$, and skin of patients with MSA, PD, and other $\alpha$-synucleinopathies, with high sensitivity and specificity [12-19]. Hence, the RT-QuIC has been increasingly used to assist in the premortem diagnosis of these pathologies, especially with regard to CSF analysis. However, the current lack of harmonized analytical procedures between laboratories hampers the possibility to carefully evaluate the overall reliability and robustness of the assay in clinical practice.

At present, only one CSF-based RT-QuIC comparative study for the diagnosis of PD has been reported [20].

An international cross-laboratory validation study of OM-based RT-QuIC analysis has never been performed and may help to carefully evaluate the sensitivity and specificity of the assay toward the diagnosis of $\mathrm{PD}$, MSA-P, and MSA-C using this biological sample. To this aim, we combined the specific RT-QuIC expertise of two laboratories, one in Italy (ITA-lab) and one in the USA (USA-lab), to set up a precise $\alpha$-synuclein RTQuIC ( $\alpha$ Syn_RT-QuIC) protocol for the analysis of OM samples collected from well-characterized patients with MSA-P, MSA-C, PD, and healthy subjects (HS). After extensive technical optimizations, we established a protocol that fulfilled our analytical needs and yielded a very high interlaboratory reproducibility of the test results. To the best of our knowledge, this is the first interlaboratory study of OM samples and our results indicate that $\alpha$ Syn_RT-QuIC may be a robust and reliable biochemical assay to accurately diagnose and discriminate PD, MSA-P, and MSA-C in living patients using an easily collectible tissue. The identification of peripheral $\alpha \operatorname{Syn}^{\mathrm{D}}$ will significantly increase the accuracy of premortem diagnosis and facilitate patients' stratification for therapeutic treatments and enrollment in clinical trials.

\section{Methods}

Study design and participants

This exploratory and prospective study involved two different laboratories, one at the Fondazione IRCCS Istituto Neurologico Carlo Besta in Italy (ITA-lab) and the other one at the Case Western Reserve University School of Medicine in USA (USA-lab). A consecutive series of well-characterized patients followed at the Parkinson and Movement Disorders Unit of ITA-lab who met established diagnostic criteria for probable MSA-P $(n=$ 
$20,55 \%$ male, mean age 60 years, mean disease duration 4.4 years), MSA-C ( $n=10,60 \%$ male, mean age 61 years, mean disease duration 4 years), PD ( $n=13,62 \%$ male, mean age 63 years, mean disease duration 8 years), and a group of HS ( $n=11,45 \%$ male, mean age 42 years) were included in the study (Table 1) $[1,21]$. The age differences between patients and healthy subjects $(61 \pm 8$ and $42 \pm 10$ years, respectively) as well as the disease duration between MSA and PD patients $(4 \pm 3.1$ and $8 \pm 4.3$ years, respectively) were statistically significant (t-test $p<0.01$ ). Extensive clinical symptoms and signs, including treatment response, presence of REM sleep behavior disorder, and red flags helping the MSA diagnosis were carefully assessed and detailed in Tables 2 and 3. The clinical diagnosis was confirmed by three independent clinicians (GD, AEE, RE) and supported by specific diagnostic tests including brain MRI, cardiovascular autonomic tests, nigrostriatal dopamine transporter imaging with 123I-ioflupane single-photon emission computed tomography, and cardiac uptake of I-123 MIBG singlephoton emission computed tomography. Motor symptoms were assessed using part III of the Movement Disorder Society-Unified Parkinson's Disease Rating Scale (MDS-UPDRS) [22]. Patients suspected to have other neurodegenerative diseases (e.g. Alzheimer's disease, progressive supranuclear palsy, corticobasal syndrome, and dementia with Lewy bodies) or other relevant clinical conditions (including stroke, neuromuscular diseases, severe osteoarthrosis, or other musculoskeletal impairments affecting gait and standing) that could have affected the clinical scales (e.g. MDS-UPDRS III, H\&Y) were excluded from the study. Similarly, patients unable to provide their informed consent were not included. All the procedures involving human participants were performed in accordance with the ethical standards of the institutional and/or national research committees and with the 1964 Helsinki declaration. The study and its ethical aspects were approved by the Fondazione IRCCS Istituto Neurologico Carlo Besta ethical committee. All of the participants provided written informed consent before OM collection and analysis.

\section{Collection of OM samples}

OM samples were collected by a specialized otorhinolaryngologist with non-invasive procedures, as previously reported [16], and before the COVID-19 pandemic. A total of $54 \mathrm{OM}$ samples were collected by gently brushing between the septum and the middle turbinate in the nasal vault with a flocked swab (FLOQSwabs ${ }^{\text {Tw }}$ Copan Italia, Brescia, Italy). All OM samples were collected at ITA-lab, processed, and divided into two aliquots: one for ITA-lab and the other for USA-lab analyses. Samples were blindly tested by both laboratories.

\section{Preparation of OM for aSyn_RT-QulC analysis}

OM samples were prepared as previously described [16]. Six $\mu \mathrm{g}$ of pelleted cells was suspended in $50 \mu \mathrm{L}$ of phosphate-buffer saline (PBS), while the remaining pellet of OM was stored at $-80^{\circ} \mathrm{C}$. Ten microliters of the sample was then diluted 20 folds in PBS (supplemented with $1 \%$ Triton-X 100) and the resulting solution was analyzed by $\alpha$ Syn_RT-QuIC.

\section{Harmonized protocol for aSyn_RT-QulC analysis}

The $\alpha$ Syn_RT-QuIC protocol for OM samples analysis was modified from that of a previous report [16] with the consideration of salt effects on RT-QuIC reactivity as recently described [23]. In brief, $\alpha$ Syn_RT-QuIC analyses were performed using 384-well optical flat bottom plates (Thermo Scientific). Each well was preloaded with two low-binding silica beads $(0.8 \mathrm{~mm}$, OPS Diagnostics). Lyophilized recombinant human $\alpha$ Syn (rec- $\alpha$ Syn), purchased from rPeptide (S-1001-2), was reconstituted in water and filtered with $100 \mathrm{kDa}$ filters immediately before use. For each well, $1 \mu \mathrm{L}$ of OM samples was added to $49 \mu \mathrm{L}$ of $\alpha$ Syn_RT-QuIC reaction mix that was composed of: rec- $\alpha$ Syn $[0.1 \mathrm{mg} / \mathrm{mL}]$, HEPES (pH 8.0) [40 mM], sodium citrate [170 mM], and thioflavin-T (ThT) $[20 \mu \mathrm{M}]$. Each sample was analyzed in quadruplicate and at least three times in both labs. The plates were incubated at $42^{\circ} \mathrm{C}$ in a BMG FluoSTAR OMEGA microplate reader (BMG Labtech) and subjected to cycles of shaking and incubation (1 min each). Under this condition, rec- $\alpha$ Syn undergoes self-assembly and forms amyloid fibrils following well-defined kinetics. The addition of a biological sample (e.g. OM), containing minute amounts of $\alpha \operatorname{Syn}^{\mathrm{D}}$, significantly increases this aggregation kinetics, producing the so-called seeding activity. Fluorescence intensities of ThT, expressed as arbitrary units (AU), were taken every $30 \mathrm{~min}$ using $450 \pm 10 \mathrm{~nm}$ (excitation) and $480 \pm 10 \mathrm{~nm}$ (emission) wave-lengths, with a bottom read. A sample was considered able to induce seeding activity when at least two out of four replicates crossed the threshold of fluorescence set at 30,000 AU before $13 \mathrm{~h}$ at ITA-lab or $22.5 \mathrm{~h}$ at USA-lab. In this case, the sample was considered positive (+). For each positive sample, we have calculated the average fluorescence intensity of the replicates that crossed the fluorescence thresholds and plotted the results in a graph against time. Results were correlated with demographic and clinical data (Table 5).

\section{Dot blot analysis of aSyn_RT-QulC reaction products}

Two $\mu \mathrm{L}$ of final $\alpha$ Syn_RT-QuIC products was diluted with $500 \mu \mathrm{L}$ of PBS containing $0.1 \%$ Tween-20. One hundred microliters of the diluted samples were loaded onto a nitrocellulose membrane $(0.2 \mu \mathrm{m}$ pore $)$ assembled in a Bio-Rad 96-well Bio-Dot apparatus per manufacturer's protocol. The membrane was blocked for $1 \mathrm{~h}$ at room temperature with $5 \%$ bovine serum albumin (BSA) made 
Table 1 Demographic data and aSyn_RT-QulC results

\begin{tabular}{|c|c|c|c|c|c|c|c|c|c|c|c|c|c|c|}
\hline \multirow[t]{2}{*}{$\begin{array}{l}\text { Clinical } \\
\text { diagnosis }\end{array}$} & \multirow[t]{2}{*}{$\begin{array}{l}\text { Sex } \\
\text { (Male) }\end{array}$} & \multirow[t]{2}{*}{$\begin{array}{l}\text { Year } \\
\text { of } \\
\text { birth }\end{array}$} & \multirow[t]{2}{*}{$\begin{array}{l}\text { Age } \\
\text { at } \\
\text { onset }\end{array}$} & \multirow{2}{*}{$\begin{array}{l}\text { Age at } \\
\text { brushing }\end{array}$} & \multirow{2}{*}{$\begin{array}{l}\text { T1 } \\
\text { (years) = } \\
\text { disease } \\
\text { duration }\end{array}$} & \multirow[t]{2}{*}{ Clinical onset } & \multirow{2}{*}{$\begin{array}{l}\text { Family } \\
\text { history of } \\
\text { parkinsonism } \\
\text { or ataxia }\end{array}$} & \multicolumn{2}{|c|}{$\begin{array}{l}\text { Time to } \\
\text { threshold }\end{array}$} & \multicolumn{2}{|c|}{$\begin{array}{l}\text { Fluorescence at } \\
\text { time threshold }\end{array}$} & \multirow{2}{*}{$\begin{array}{l}\text { Mean } \\
\text { intensity } \\
\text { at PK } \\
2.5 \mathrm{mg} / \\
\mathrm{mL} \text { (ITA- } \\
\text { lab) }\end{array}$} & \multicolumn{2}{|c|}{$\begin{array}{l}\text { aSyn_RT- } \\
\text { QulC } \\
\text { results }\end{array}$} \\
\hline & & & & & & & & $\begin{array}{l}\text { ITA- } \\
\text { lab }\end{array}$ & $\begin{array}{l}\text { USA- } \\
\text { lab }\end{array}$ & $\begin{array}{l}\text { ITA- } \\
\text { lab }\end{array}$ & $\begin{array}{l}\text { USA- } \\
\text { lab }\end{array}$ & & $\begin{array}{l}\text { ITA- } \\
\text { lab }\end{array}$ & $\begin{array}{l}\text { USA- } \\
\text { lab }\end{array}$ \\
\hline PD_1 & + & 1956 & 55 & 61 & 6 & $\begin{array}{l}\text { (rest) tremor at } \\
\text { left hand }\end{array}$ & - & 9.00 & 9.44 & 260,000 & 260,000 & 9.56 & + & + \\
\hline PD_2 & - & 1947 & 63 & 71 & 8 & $\begin{array}{l}\text { rigidity right } \\
\text { hand }\end{array}$ & - & 9.5 & 11.25 & 260,000 & 250,509 & 5.67 & + & + \\
\hline PD_3 & + & 1952 & 54 & 66 & 12 & $\begin{array}{l}\text { bradykinesia } \\
\text { and rigidity left } \\
\text { hand }\end{array}$ & - & 10.25 & 12.44 & 171,531 & 260,000 & 5.59 & + & + \\
\hline PD_4 & - & 1959 & 50 & 59 & 9 & $\begin{array}{l}\text { rigidity right } \\
\text { hand }\end{array}$ & - & NA & NA & 14,452 & 6607 & 5.85 & - & - \\
\hline PD_5 & + & 1945 & 61 & 74 & 13 & $\begin{array}{l}\text { rigidity and } \\
\text { tremor }\end{array}$ & - & NA & NA & 14,026 & 7283 & 7.02 & - & - \\
\hline PD_6 & + & 1967 & 48 & 52 & 4 & dysautonomia & + & NA & NA & 13,370 & 13,623 & 6.41 & - & - \\
\hline PD_7 & + & 1967 & 49 & 51 & 2 & $\begin{array}{l}\text { bradykinesia } \\
\text { and tremor }\end{array}$ & - & 7.5 & 14.13 & 259,150 & 260,000 & 59.39 & + & + \\
\hline PD_8 & - & 1952 & 50 & 67 & 17 & $\begin{array}{l}\text { bradykinesia } \\
\text { and rigidity left } \\
\text { hand }\end{array}$ & - & NA & NA & 17,385 & 8232 & 5.29 & - & - \\
\hline PD_9 & - & 1950 & 59 & 67 & 8 & rigidity & - & 11.33 & 19.5 & 121,284 & 49,958 & 12.32 & + & + \\
\hline PD_10 & + & 1961 & 53 & 58 & 5 & dysautonomia & - & 10.33 & 21.00 & 120,929 & 55,342 & 6.63 & + & + \\
\hline PD_11 & + & 1962 & 52 & 58 & 6 & $\begin{array}{l}\text { rigidity and } \\
\text { frozen shoulder }\end{array}$ & - & 8.88 & 15.08 & 169,629 & 159,598 & 8.19 & + & + \\
\hline PD_12 & - & 1947 & 69 & 72 & 3 & $\begin{array}{l}\text { bradykinesia } \\
\text { and rigidity left } \\
\text { leg }\end{array}$ & + & 9.00 & 20.25 & 222,667 & 49,532 & 6.49 & + & + \\
\hline PD_13 & + & 1951 & 55 & 66 & 11 & $\begin{array}{l}\text { bradykinesia } \\
\text { and tremor }\end{array}$ & - & 8.00 & 20.25 & 260,000 & 35,814 & 11.58 & + & + \\
\hline MSA-P_1 & - & 1947 & 67 & 70 & 3 & dysautonomia & - & 10.67 & 14.56 & 183,784 & 215,981 & 81.11 & + & + \\
\hline MSA-P_2 & + & 1948 & 69 & 71 & 2 & parkinsonism & - & 10.25 & 20.88 & 173,619 & 56,919 & 56.09 & + & + \\
\hline MSA-P_3 & + & 1964 & 48 & 53 & 5 & $\begin{array}{l}\text { RBD and later } \\
\text { parkinsonism }\end{array}$ & - & 10.00 & 12.69 & 227,396 & 239,598 & 21.67 & + & + \\
\hline MSA-P_4 & + & 1965 & 50 & 53 & 3 & parkinsonism & - & 12.33 & 18.13 & 41,279 & 196,898 & 56.97 & + & + \\
\hline MSA-P_5 & + & 1957 & 56 & 62 & 6 & dysautonomia & - & 11.75 & 17.25 & 56,628 & 183,834 & 21.57 & + & + \\
\hline MSA-P_6 & - & 1957 & 54 & 61 & 7 & parkinsonism & - & 10.00 & 17.08 & 204,429 & 206,638 & 6.71 & + & + \\
\hline MSA-P_7 & - & 1946 & 72 & 73 & 1 & dysautonomia & - & 11.50 & 10.19 & 86,628 & 88,018 & 82.57 & + & + \\
\hline MSA-P_8 & + & 1973 & 40 & 46 & 6 & parkinsonism & - & 11.50 & 16.92 & 109,166 & 47,076 & 9.69 & + & + \\
\hline MSA-P_9 & + & 1976 & 39 & 44 & 5 & dysautonomia & - & 8.50 & 14.50 & 248,346 & 59,610 & 18.36 & + & + \\
\hline MSA-P_10 & + & 1962 & 55 & 57 & 2 & $\begin{array}{l}\text { RBD and later } \\
\text { parkinsonism }\end{array}$ & - & NA & NA & NA & NA & 7.27 & - & - \\
\hline MSA-P_11 & - & 1959 & 58 & 60 & 2 & parkinsonism & - & NA & NA & NA & NA & 6.98 & - & - \\
\hline MSA-P_12 & - & 1958 & 57 & 60 & 3 & parkinsonism & - & 9.67 & 20.75 & 147,488 & 135,777 & 42.32 & + & + \\
\hline MSA-P_13 & + & 1963 & 51 & 56 & 5 & dysautonomia & - & 10.50 & 18.67 & 218,123 & 82,606 & 10.26 & + & + \\
\hline MSA-P_14 & - & 1963 & 55 & 56 & 1 & parkinsonism & - & 10.50 & 17.63 & 160,382 & 260,000 & 18.2 & + & + \\
\hline MSA-P_15 & - & 1965 & 41 & 54 & 13 & parkinsonism & - & 9.50 & 20.33 & 213,766 & 84,203 & 5.77 & + & + \\
\hline MSA-P_16 & + & 1953 & 60 & 64 & 4 & $\begin{array}{l}\text { bradykynesia } \\
\text { parkinsonism }\end{array}$ & - & 11.00 & 22.50 & 133,273 & 148,704 & 8.24 & + & + \\
\hline MSA-P_17 & + & 1949 & 69 & 70 & 1 & parkinsonism & - & 10.63 & 19.13 & 224,756 & 235,573 & 95.5 & + & + \\
\hline MSA-P_18 & - & 1963 & 61 & 65 & 4 & parkinsonism & - & 8.33 & 20.00 & 260,000 & 30,995 & 42.27 & + & + \\
\hline
\end{tabular}


Table 1 Demographic data and aSyn_RT-QulC results (Continued)

\begin{tabular}{|c|c|c|c|c|c|c|c|c|c|c|c|c|c|c|}
\hline \multirow[t]{2}{*}{$\begin{array}{l}\text { Clinical } \\
\text { diagnosis }\end{array}$} & \multirow[t]{2}{*}{$\begin{array}{l}\text { Sex } \\
\text { (Male) }\end{array}$} & \multirow[t]{2}{*}{$\begin{array}{l}\text { Year } \\
\text { of } \\
\text { birth }\end{array}$} & \multirow[t]{2}{*}{$\begin{array}{l}\text { Age } \\
\text { at } \\
\text { onset }\end{array}$} & \multirow[t]{2}{*}{$\begin{array}{l}\text { Age at } \\
\text { brushing }\end{array}$} & \multirow{2}{*}{$\begin{array}{l}\text { T1 } \\
\text { (years)= } \\
\text { disease } \\
\text { duration }\end{array}$} & \multirow[t]{2}{*}{ Clinical onset } & \multirow{2}{*}{$\begin{array}{l}\text { Family } \\
\text { history of } \\
\text { parkinsonism } \\
\text { or ataxia }\end{array}$} & \multicolumn{2}{|c|}{$\begin{array}{l}\text { Time to } \\
\text { threshold }\end{array}$} & \multicolumn{2}{|c|}{$\begin{array}{l}\text { Fluorescence at } \\
\text { time threshold }\end{array}$} & \multirow{2}{*}{$\begin{array}{l}\text { Mean } \\
\text { intensity } \\
\text { at PK } \\
2.5 \mathrm{mg} / \\
\mathrm{mL} \text { (ITA- } \\
\text { lab) }\end{array}$} & \multicolumn{2}{|c|}{$\begin{array}{l}\text { aSyn_RT- } \\
\text { QuIC } \\
\text { results }\end{array}$} \\
\hline & & & & & & & & $\begin{array}{l}\text { ITA- } \\
\text { lab }\end{array}$ & $\begin{array}{l}\text { USA- } \\
\text { lab }\end{array}$ & $\begin{array}{l}\text { ITA- } \\
\text { lab }\end{array}$ & $\begin{array}{l}\text { USA- } \\
\text { lab }\end{array}$ & & $\begin{array}{l}\text { ITA- } \\
\text { lab }\end{array}$ & $\begin{array}{l}\text { USA- } \\
\text { lab }\end{array}$ \\
\hline MSA-P_19 & + & 1959 & 58 & 60 & 2 & parkinsonism & - & 10.33 & 16.33 & 183,011 & 50,658 & 34.47 & + & + \\
\hline MSA-P_20 & - & 1953 & 52 & 65 & 13 & parkinsonism & + & 12.75 & 12.63 & 43,645 & 57,486 & 5.85 & + & + \\
\hline MSA-C_1 & - & 1965 & 45 & 54 & 9 & cerebellar & - & NA & NA & NA & NA & 2.86 & - & - \\
\hline MSA-C_2 & + & 1947 & 70 & 72 & 2 & cerebellar & - & NA & NA & NA & NA & 3.07 & - & - \\
\hline MSA-C_3 & - & 1957 & 57 & 62 & 5 & $\mathrm{RBD}$ & - & NA & NA & NA & NA & 3.09 & - & - \\
\hline MSA-C_4 & + & 1971 & 47 & 48 & 1 & cerebellar & - & NA & NA & NA & NA & 3.37 & - & - \\
\hline MSA-C_5 & - & 1950 & 64 & 69 & 5 & cerebellar & - & NA & NA & NA & NA & 3.76 & - & - \\
\hline MSA-C_6 & + & 1964 & 50 & 55 & 5 & cerebellar & - & NA & NA & NA & NA & 3.86 & - & - \\
\hline MSA-C_7 & + & 1950 & 69 & 70 & 1 & cerebellar & - & NA & NA & NA & NA & 4.4 & - & + \\
\hline MSA-C_8 & + & 1965 & 51 & 55 & 4 & dysautonomia & - & NA & NA & NA & NA & 4.86 & - & - \\
\hline MSA-C_9 & - & 1948 & 67 & 70 & 3 & cerebellar & - & NA & NA & NA & NA & 4.68 & - & - \\
\hline $\begin{array}{l}\text { MSA-C_ } \\
10\end{array}$ & + & 1965 & 50 & 55 & 5 & cerebellar & - & NA & NA & NA & NA & 3.59 & - & - \\
\hline HS_1 & + & 1955 & NA & 64 & NA & NA & NA & NA & NA & NA & NA & 4.22 & - & - \\
\hline HS_2 & + & 1981 & NA & 38 & NA & NA & NA & NA & NA & NA & NA & 3.98 & - & - \\
\hline HS_3 & - & 1985 & NA & 35 & NA & NA & NA & NA & NA & NA & NA & 3.03 & - & - \\
\hline HS_4 & - & 1987 & NA & 32 & NA & NA & NA & NA & NA & NA & NA & 3.44 & - & - \\
\hline HS_5 & - & 1969 & NA & 50 & NA & NA & NA & NA & NA & NA & NA & 2.12 & - & - \\
\hline HS_6 & + & 1979 & NA & 38 & NA & NA & NA & NA & NA & NA & NA & 3.33 & - & - \\
\hline HS_7 & - & 1984 & NA & 35 & NA & NA & NA & NA & NA & NA & NA & 3.17 & - & - \\
\hline HS_8 & - & 1979 & NA & 39 & NA & NA & NA & NA & NA & NA & NA & 3.04 & - & + \\
\hline HS_9 & + & 1974 & NA & 45 & NA & NA & NA & NA & NA & NA & NA6 & 2.87 & - & - \\
\hline HS_10 & - & 1970 & NA & 49 & NA & NA & NA & NA & NA & NA & NA & 2.21 & - & - \\
\hline HS_11 & + & 1985 & NA & 34 & NA & NA & NA & NA & NA & NA & NA & 2.78 & - & - \\
\hline
\end{tabular}

in PBS (5\% BSA-PBS). The membrane was then incubated for $1 \mathrm{~h}$ with a rabbit monoclonal $\alpha$ Syn filament-specific antibody (Abcam ab209538, diluted 1:5,000 in 5\% BSA-PBS) or a rabbit polyclonal total $\alpha$ Syn antibody (Millipore Ab5038, diluted 1:1,000 in 5\% BSA-PBS). After washing 3 times with Tris-buffered saline containing 0.1\% Tween-20 (TBST-0.1), the membrane was incubated for $1 \mathrm{~h}$ with a secondary antibody (Amersham donkey against rabbit IgG-HRP, diluted 1: 10,000 in $5 \%$ BSA-PBS). Following three washes with TBST0.1 , the immunoreactivity on the dot-blotted membrane was developed with the enhanced chemiluminescence reagents (ECL, Amersham). The densitometric quantitation of the individual dots was performed with the Epson Perfection V600 photo scanner (Epson Scan Utility v3.9.2).

\section{Protease resistance analysis of aSyn_RT-QuIC reaction products}

Eight $\mu \mathrm{L}$ of final $\alpha$ Syn_RT-QuIC products was treated with proteinase $\mathrm{K}$ (PK, Invitrogen) $[2.5 \mathrm{mg} / \mathrm{mL}]$ for $1 \mathrm{~h}$ at $37^{\circ} \mathrm{C}$ (under shaking at $500 \mathrm{rpm}$ ). PK digestions were stopped by the addition of the LDS-PAGE loading buffer (Bolt ${ }^{\text {tix }}$ LDS Sample Buffer and DTT, Thermo Scientific) and by boiling the samples at $100{ }^{\circ} \mathrm{C}$ for $10 \mathrm{~min}$ (under shaking at $500 \mathrm{rpm}$ ). Proteins were then separated by means of SDS-PAGE, using $12 \%$ Bis-Tris plus gels (Thermo Scientific), and transferred onto polyvinylidene difluoride (PVDF) membranes (Immobilon-P, Millipore). PVDF membranes were incubated with paraformaldehyde $(0.4 \%$ in PBS) for $30 \mathrm{~min}$ at room temperature (under shaking) and subsequently incubated with nonfat dry milk (prepared in TBS with 0.05\% Tween-20, TBST-0.05) for $1 \mathrm{~h}$ at room temperature. Membranes were then incubated with a rabbit polyclonal $\alpha$-synuclein antibody (Agrisera AS08 358, diluted 1:1000 in TBST0.05 ) overnight at $4{ }^{\circ} \mathrm{C}$ (under shaking). After three washes in TBST-0.05, membranes were incubated with a secondary antibody (Amersham donkey against rabbit IgG-HRP, diluted 1:2,000 in TBST-0.05 supplemented 


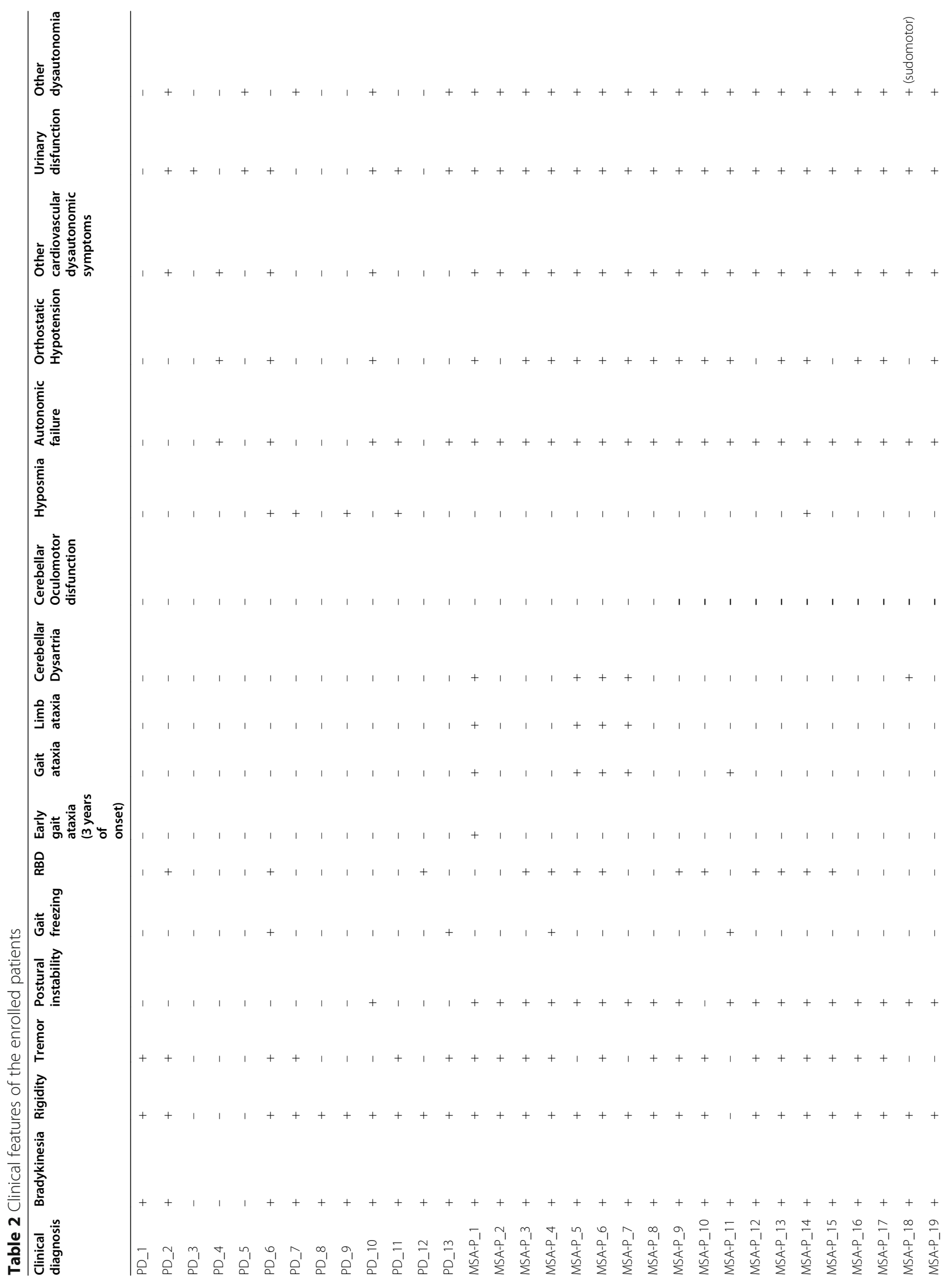




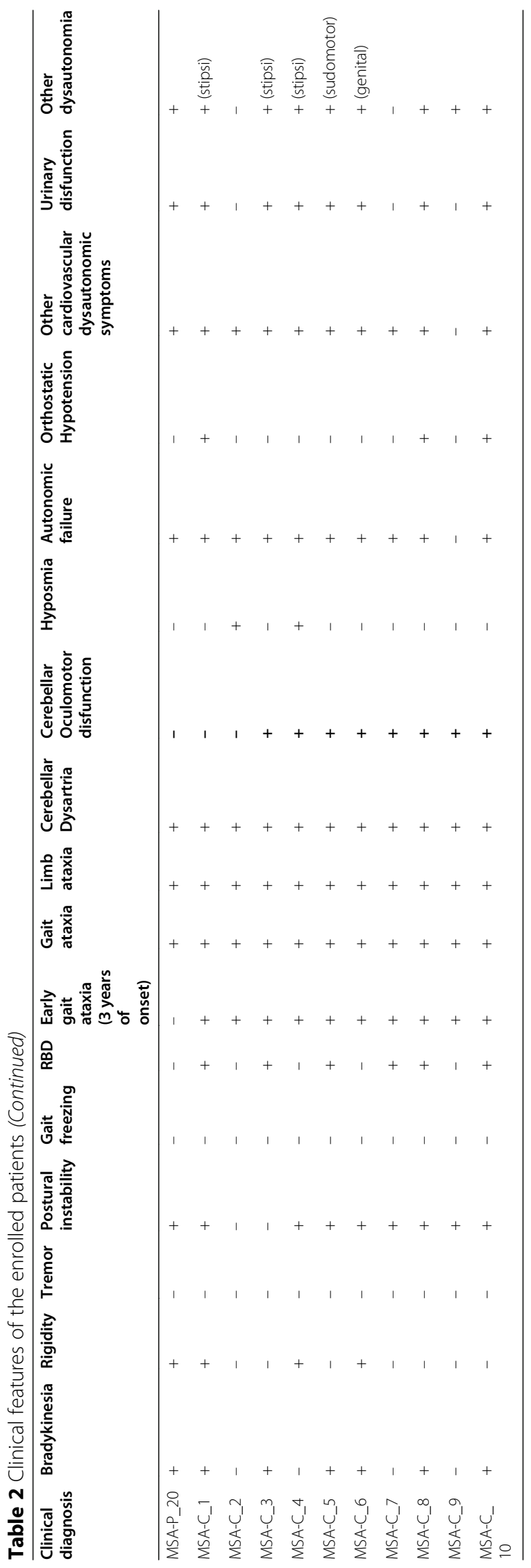


Table 3 Instrumental findings and additional features supportive for the clinical diagnosis

\begin{tabular}{|c|c|c|c|c|c|c|c|c|c|c|}
\hline \multirow{2}{*}{$\begin{array}{l}\text { Clinical } \\
\text { diagnosis }\end{array}$} & \multirow{2}{*}{$\begin{array}{l}\text { Disease } \\
\text { duration } \\
\text { at } \\
\text { sampling } \\
\text { (years) }\end{array}$} & \multirow[t]{2}{*}{ Parkinsonism } & \multirow[b]{2}{*}{$\begin{array}{l}\text { Beneficial } \\
\text { L-Dopa } \\
\text { response } \\
\text { (MDS- } \\
\text { UPDRS-III } \\
\text { CHANGE } \\
\% \text { ) }\end{array}$} & \multirow{2}{*}{$\begin{array}{l}\text { Cerebellar } \\
\text { syndrome }\end{array}$} & \multicolumn{3}{|c|}{ MRI abnormalities } & \multirow{2}{*}{$\begin{array}{l}\text { FDG- } \\
\text { PET }\end{array}$} & \multirow{2}{*}{$\begin{array}{l}\text { SPET- } \\
\text { DATS } \\
\text { CAN }\end{array}$} & \multirow{2}{*}{ MIBG } \\
\hline & & & & & $\begin{array}{l}\text { Putaminal slit } \\
\text { sign }\end{array}$ & $\begin{array}{l}\text { Middle cerebellar } \\
\text { peduncle }\end{array}$ & $\begin{array}{l}\text { Cerebellum } \\
\text { atrophy }\end{array}$ & & & \\
\hline PD_1 & 6 & + & 37 & - & - & - & - & NA & + & NA \\
\hline PD_2 & 8 & + & 48 & - & - & - & - & NA & + & NA \\
\hline PD_3 & 12 & + & 27 & - & - & - & - & NA & + & NA \\
\hline PD_4 & 9 & + & 29 & - & - & - & - & NA & + & + \\
\hline PD_5 & 13 & + & 31 & - & - & - & - & NA & + & NA \\
\hline PD_6 & 4 & + & 23 & - & - & - & - & NA & + & + \\
\hline PD_7 & 2 & + & 27 & - & - & - & - & NA & + & NA \\
\hline PD_8 & 17 & + & 31 & - & - & - & - & NA & + & NA \\
\hline PD_9 & 8 & + & 29 & - & - & - & - & NA & + & NA \\
\hline PD_10 & 5 & + & 30 & - & - & - & - & NA & + & + \\
\hline PD_11 & 6 & + & 21 & - & - & - & - & - & + & + \\
\hline PD_12 & 3 & + & 35 & - & - & - & - & - & + & + \\
\hline PD_13 & 11 & + & 23 & - & - & - & - & - & + & NA \\
\hline MSA-P_1 & 3 & + & 29 & + & + & + & + & NA & + & - \\
\hline MSA-P_2 & 2 & + & 14 & - & + & - & - & NA & + & - \\
\hline MSA-P_3 & 5 & + & 24 & - & + & - & - & NA & + & NA \\
\hline MSA-P_4 & 3 & + & 16 & - & + & + & + & NA & + & - \\
\hline MSA-P_5 & 6 & + & 18 & + & - & - & - & NA & + & - \\
\hline MSA-P_6 & 7 & + & 12 & - & - & + & + & NA & + & NA \\
\hline MSA-P_7 & 1 & + & 12 & + & + & - & - & NA & + & + \\
\hline MSA-P_8 & 6 & + & 16 & - & + & - & - & NA & + & - \\
\hline MSA-P_9 & 5 & + & 9 & - & + & - & - & NA & + & $\begin{array}{l}\text { mild } \\
\text { pos }\end{array}$ \\
\hline MSA-P_10 & 2 & + & 6 & - & + & - & + & NA & + & - \\
\hline MSA-P_11 & 2 & + & 10 & + & + & - & + & NA & + & - \\
\hline MSA-P_12 & 3 & + & 13 & - & + & - & + & NA & + & - \\
\hline MSA-P_13 & 5 & + & 22 & - & - & - & - & NA & + & - \\
\hline MSA-P_14 & 1 & + & 13 & - & - & - & - & NA & + & - \\
\hline MSA-P_15 & 13 & + & 14 & - & - & - & - & - & + & - \\
\hline MSA-P_16 & 4 & + & 9 & - & - & - & - & - & + & - \\
\hline MSA-P_17 & 1 & + & 11 & - & - & - & - & - & - & - \\
\hline MSA-P_18 & 4 & + & 0 & + & - & - & - & - & - & + \\
\hline MSA-P_19 & 2 & + & 5 & - & - & - & - & - & - & - \\
\hline MSA-P_20 & 13 & + & 13 & + & + & + & + & - & + & NA \\
\hline MSA-C_1 & 9 & + & 14 & + & - & - & - & NA & + & NA \\
\hline MSA-C_2 & 2 & - & 10 & + & + & + & + & NA & + & - \\
\hline MSA-C_3 & 5 & - & 22 & + & + & + & + & NA & + & NA \\
\hline MSA-C_4 & 1 & - & 13 & + & + & + & + & NA & + & - \\
\hline MSA-C_5 & 5 & + & 14 & + & + & + & + & NA & + & - \\
\hline MSA-C_6 & 5 & + & 31 & + & + & + & + & NA & + & NA \\
\hline MSA-C_7 & 1 & - & 29 & + & + & + & + & + & - & NA \\
\hline
\end{tabular}


Table 3 Instrumental findings and additional features supportive for the clinical diagnosis (Continued)

\begin{tabular}{|c|c|c|c|c|c|c|c|c|c|c|}
\hline \multirow{2}{*}{$\begin{array}{l}\text { Clinical } \\
\text { diagnosis }\end{array}$} & \multirow{2}{*}{$\begin{array}{l}\text { Disease } \\
\text { duration } \\
\text { at } \\
\text { sampling } \\
\text { (years) }\end{array}$} & \multirow[t]{2}{*}{ Parkinsonism } & \multirow[b]{2}{*}{$\begin{array}{l}\text { Beneficial } \\
\text { L-Dopa } \\
\text { response } \\
\text { (MDS- } \\
\text { UPDRS-III } \\
\text { CHANGE } \\
\% \text { ) }\end{array}$} & \multirow{2}{*}{$\begin{array}{l}\text { Cerebellar } \\
\text { syndrome }\end{array}$} & \multicolumn{3}{|c|}{ MRI abnormalities } & \multirow{2}{*}{$\begin{array}{l}\text { FDG- } \\
\text { PET }\end{array}$} & \multirow{2}{*}{$\begin{array}{l}\text { SPET- } \\
\text { DATS } \\
\text { CAN }\end{array}$} & \multirow{2}{*}{ MIBG } \\
\hline & & & & & $\begin{array}{l}\text { Putaminal slit } \\
\text { sign }\end{array}$ & $\begin{array}{l}\text { Middle cerebellar } \\
\text { peduncle }\end{array}$ & $\begin{array}{l}\text { Cerebellum } \\
\text { atrophy }\end{array}$ & & & \\
\hline MSA-C_8 & 4 & - & 22 & + & - & + & + & + & - & - \\
\hline MSA-C_99 & 3 & - & 11 & + & - & + & + & NA & - & NA \\
\hline $\begin{array}{l}\text { MSA-C_ } \\
10\end{array}$ & 5 & + & 10 & + & + & - & - & NA & + & - \\
\hline
\end{tabular}

with $5 \%$ non-fat dry milk) for $1 \mathrm{~h}$ at room temperature (under shaking) and developed with a chemiluminescent system (ECL Prime, Amersham). Finally, reactions were visualized using a G:BOX Chemi Syngene system. Densitometric analysis of Western blot bands was carried out using ImageJ software $(1.51 \mathrm{v})$.

\section{Statistical analysis}

$\alpha$ Syn_RT-QuIC kinetics were represented using the Prism software (GraphPad v9.0.0) on a graph where mean fluorescence values were plotted against time. For each patient, we calculated the average times at which the positive replicates crossed the predefined threshold of 30,000 AU (time to threshold). The mean fluorescence intensity reached by each patient at $13 \mathrm{~h}$ at ITA-lab or $22.5 \mathrm{~h}$ at USA-lab was used to calculate the fluorescence values at the time threshold. Graphic representations of densitometric analysis were performed using the Prism software (GraphPad v9.0.0). Associations between variables were investigated through t-test or Mann-Whitney test, Chi-square or Fisher exact test, as appropriate. Dot blot results and PK resistance profiles of $\alpha$ Syn_RT-QuIC products generated by PD and MSA were analyzed through repeated measure analysis of variance (ANOVA). Given the exploratory nature of our study, the calculation of the power analysis was not performed. Kappa statistic with the corresponding 95\% confidence interval (CI) was calculated to assess interrater agreement between ITA-lab and USA-lab.

\section{Results}

Efficient aSyn_RT-QulC seeding activity was observed in OM of PD and MSA-P patients but not in those of MSA-C patients

The USA-lab introduced some important modifications to the RT-QuIC protocol published in 2019 [16] by some of the authors of this paper for the analysis of OM samples.

Following the validation of the $\alpha$ Syn_RT-QuIC protocol using the brain homogenates of autopsy-confirmed cases of PD, MSA-P, and MSA-C as sources of different $\alpha \operatorname{Syn}^{\mathrm{D}}$ strains (see Supplementary Fig. 1), ITA-lab and USA-lab performed blind $\alpha$ Syn_RT-QuIC analyses of OM samples collected from PD (\% mean MDS-UPDRS Gain 30.1), MSA-P (\% mean MDS-UPDRS Gain 13.3), MSA-C (\% mean MDS-UPDRS Gain 17.6) patients as well as HS. The demographic data and the $\alpha$ Syn_RTQuIC results, the clinical features and the instrumental findings of the patients included in the study are reported in Tables 1, 2 and 3, respectively.

Graphical representations of the $\alpha$ Syn_RT-QuIC seeding activities of each OM sample obtained in both labs are shown in Fig. 1. According to lab-specific time thresholds, we observed that the OM of the same PD patients (9/13) and MSA-P patients (18/20) consistently induced a seeding activity for rec- $\alpha$ Syn thus yielding a $100 \%$ interlaboratory reproducibility of the results (Fig. 1a,b,c,d).

Notably, at ITA-lab the OM of PD patients induced faster rec- $\alpha$ Syn aggregation compared to those of MSA$\mathrm{P}$ and the time to threshold (mean \pm standard deviation) of PD $(9.31 \pm 1.19 \mathrm{~h})$ was statistically different from that of MSA-P $(10.54 \pm 1.17 \mathrm{~h})$ (t-test, $p=0.0170)$ (Supplementary Fig. 2). In contrast, at USA-lab the time to threshold of PD and MSA-P samples $(15.93 \pm 4.41 \mathrm{~h}$ and $17.23 \pm 3.29 \mathrm{~h}$, respectively) was not statistically different (t-test, $p=0.3944$ ). Similarly, both laboratories did not observe differences in the average fluorescence values reached by PD and MSA-P at the time thresholds (Supplementary Fig. 2).

With respect to the clinical diagnosis, we obtained a 90\% sensitivity of $\alpha$ Syn_RT-QuIC seeding activity in OM samples of patients with MSA-P while that of PD patients was $69 \%$ (slightly higher than that published in 2019 [16]) (Table 4). Surprisingly, except for one OM at USA-lab, none of the MSA-C samples induced $\alpha S y n$ RT-QuIC seeding activity, leading to a $90 \%$ interrater agreement of results (IAR) (Fig. 1e,f and Table 4). Thus, the opposite $\alpha$ Syn_RT-QuIC analytical responsiveness of MSA-C and MSA-P, constantly observed in both laboratories, enabled efficient discrimination between disease phenotypes. Finally, none of the OM collected from HS 
a

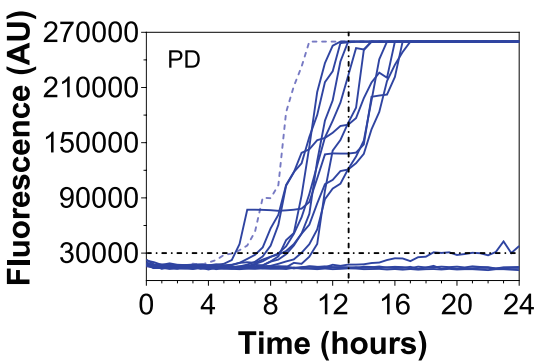

c

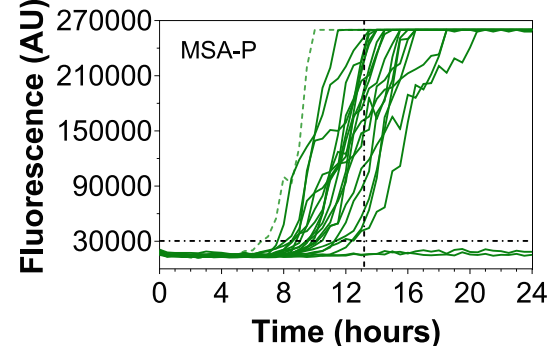

e

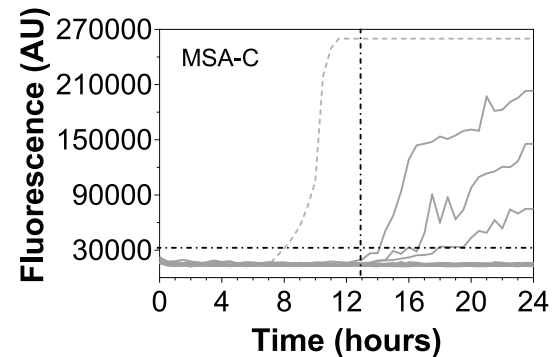

g

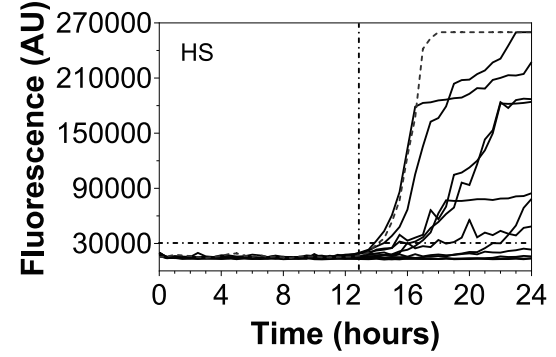

b

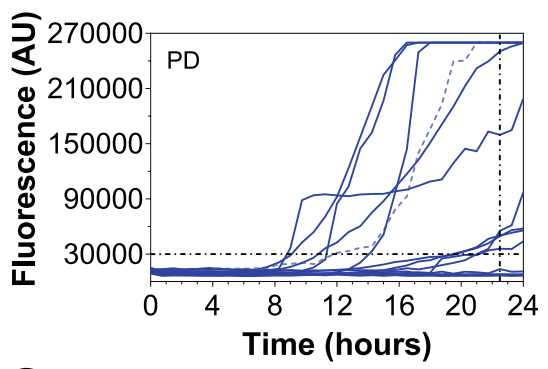

d

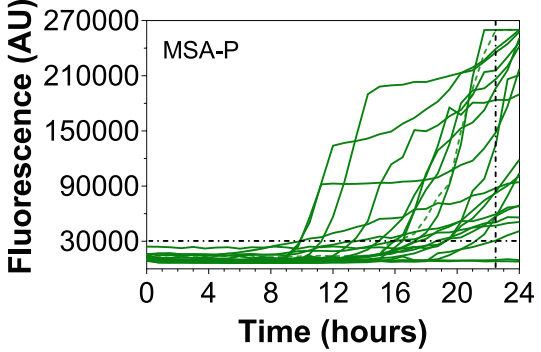

f

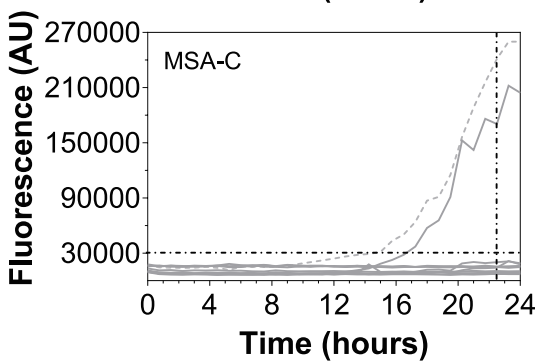

h

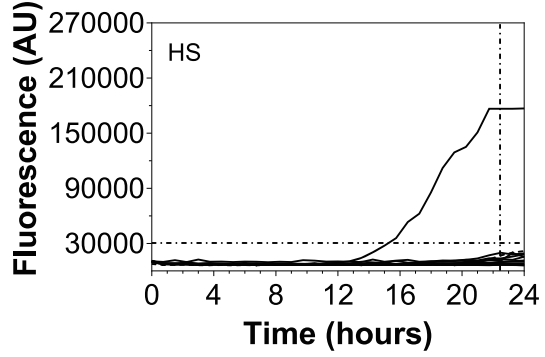

Fig. 1 Evaluation of aSyn_RT-QulC seeding activity triggered by the OM of patients with PD, MSA-P, MSA-C, and HS. RT-QulC seeding activity of aSyn ${ }^{\mathrm{D}}$ was observed in 9/13 OM samples of the same PD patients ( $\mathbf{a}$ and $\mathbf{b}$ ) and 18/20 of the same MSA-P patients (c and $\mathbf{d}$ ) analyzed at ITA-lab (a and $\mathbf{c}$ ) and USA-lab (b and $\mathbf{d}$ ). None of the samples collected from MSA-C (e) or HS (g) induced a seeding activity at ITA-lab, while 1/10 OM sample collected from MSA-C patients $(\mathbf{f})$ and 1/11 sample collected from HS (h) induced a seeding activity at USA-lab. Samples were analyzed at least three times in quadruplicate. Curves represented in the graphs were obtained by plotting the average fluorescence intensities of each sample against time. The brain homogenates (BH) of PD (dashed curves in $\mathbf{a}$ and $\mathbf{b}$ ), MSA-P (dashed curves in $\mathbf{c}$ and $\mathbf{d}$ ) and MSA-C (dashed curves in $\mathbf{e}$ and $\mathbf{f}$ ) patients were diluted until $10^{-4}$ and used as positive controls. The $\mathrm{BH}$ of a patient not affected by a-synucleinopathy (dashed curves in $\mathbf{g}$ and $\mathbf{h}$ ) was diluted until $10^{-4}$ and used as negative control

induced seeding activity, except for one sample at USAlab (Fig. 1g,h and Table 4). This yielded a 91\% IAR between laboratories. Taken together, these data led to an overall 96\% IAR between ITA-lab and USA-lab (Kappa = 0.93, 95\% CI 0.83-1.00) (Table 4). Thus, the optimized aSyn_RT-QuIC analyses enabled high levels of discrimination between (i) MSA-P and MSA-C (chi-square test, $p<0.001$ based on both ITA-lab and USA-lab findings), (ii) MSA-P and HS (chi-square test, $p<0.001$ based on both ITA-lab and USA-lab findings), and (iii) PD and HS (chi-square test, $p \leq 0.001$ and $p=0.003$ based on
ITA-lab and USA-lab findings, respectively) with a specificity of $91 \%$. Notably, repeated cycles of freezing and thawing of the OM samples did not affect their $\alpha S_{y}$ RT-QuIC behavior.

aSyn_RT-QuIC seeding activity of OM samples significantly correlated with patient rigidity and postural instability

We then performed association analyses between $\alpha$ Syn $_{-}$ RT-QuIC seeding activity in PD and MSA-P patients and several clinical parameters (see Table 5) A 
Table 4 Comparison of aSyn_RT-QulC results between ITA-lab and USA-lab

\begin{tabular}{|c|c|c|c|c|c|c|c|c|}
\hline & \multicolumn{2}{|l|}{ PD } & \multicolumn{2}{|l|}{ MSA-P } & \multicolumn{2}{|l|}{ MSA-C } & \multicolumn{2}{|l|}{ HS } \\
\hline & ITA-lab & USA-lab & ITA-lab & USA-lab & ITA-lab & USA-lab & ITA-lab & USA-lab \\
\hline Samples analyzed & 13 & 13 & 20 & 20 & 10 & 10 & 11 & 11 \\
\hline aSyn ${ }^{D}$ seeding activity & 9 & 9 & 18 & 18 & 0 & 1 & 0 & 1 \\
\hline Mean fluorescence at the time threshold \% (SD) & $\begin{array}{l}56.46 \\
(39.88)\end{array}$ & $\begin{array}{l}41.85 \\
(42.41)\end{array}$ & $\begin{array}{l}56.70 \\
(30.76)\end{array}$ & $\begin{array}{l}46.10 \\
(32.20)\end{array}$ & $\begin{array}{l}5.90 \\
(0.99)\end{array}$ & $\begin{array}{l}11.00 \\
(19.40)\end{array}$ & $\begin{array}{l}6.18 \\
(1.07)\end{array}$ & $\begin{array}{l}10.00 \\
(19.29)\end{array}$ \\
\hline Mean time at fluorescence threshold (SD) & $9.31(1.19)$ & $\begin{array}{l}15.93 \\
(4.41)\end{array}$ & $\begin{array}{l}10.54 \\
(1.17)\end{array}$ & $\begin{array}{l}17.23 \\
(3.29)\end{array}$ & NA & NA & NA & NA \\
\hline Seeding activity vs clinical diagnosis (sensitivity) & $69 \%$ & $69 \%$ & $90 \%$ & $90 \%$ & $0 \%$ & $10 \%$ & NA & NA \\
\hline Disease-specific interrater agreement between labs & $100 \%$ & & $100 \%$ & & $90 \%$ & & $91 \%$ & \\
\hline Overall interrater agreement between labs & \multicolumn{8}{|c|}{$96 \%($ Карра $=0.93,95 \%$ Cl 0.83-1.00) } \\
\hline
\end{tabular}

significant positive association was found between $\alpha \mathrm{Syn}_{-}$ RT-QuIC seeding activity and rigidity (seeding activity was present in $89.7 \%$ or $25.0 \%$ of patients with vs without rigidity, Fisher exact test, $p=0.014$ ) and postural instability (seeding activity was present in $95.0 \%$ or $61.5 \%$ of patients with vs without postural instability, Fisher exact test, $p=0.025$ ). Furthermore, there was a trend toward greater seeding activity prevalence, albeit not statistically significant, in patients with bradykinesia compared to those without symptom $(86.7 \%$ vs $33.3 \%$, Fisher exact test, $p=0.078$ ). Finally, an inverse, although not statistically significant, association was observed between seeding activity and disease duration (7.8 vs 5.4 years in patients without vs with seeding activity respectively, t-test, $p=0.19$ ). Similar results were observed considering separately PD and MSA-P patients groups.

\section{The biochemical properties of aSyn_RT-QuIC end products enabled an efficient discrimination between a- synucleinopathies}

The $\alpha$ Syn_RT-QuIC products seeded with OM samples of PD, MSA-P, MSA-C, and HS were subjected to dot blot immunoassay with a conformation-specific antibody against $\alpha$ Syn filament and revealed the presence of filament-specific $\alpha$ Syn only in samples that induced rec$\alpha$ Syn aggregation (Fig. 2a,b and Supplementary Fig. 3b). No significant differences were observed in the total levels of $\alpha$ Syn among different groups (Fig. 2a,c and Supplementary Fig. 3b). Therefore, the seeding activity of $\alpha$ Syn_RT-QuIC reactions induced by OM samples from PD and MSA-P can be accounted for by the newly formed $\alpha$ Syn fibrils. In contrast, the lack of seeding activity in OM samples from MSA-C and HS is consistent with the absence of detectable $\alpha$ Syn fibrils following $\alpha$ Syn_RT-QuIC reactions.

The same OM-seeded $\alpha$ Syn_RT-QuIC products were then subjected to Western blot analysis after PK treatment and showed the presence of PK-resistant bands in 14/18 MSA-P (78\%) and 6/9 (67\%) PD samples that induced rec- $\alpha$ Syn aggregation (Fig. 3a,b and Supplementary Fig. 3a). Notably, the bands observed in MSA-P were significantly more resistant to digestion than those observed in PD (Mann-Whitney test, $p=0.0104$ ) (Fig. 3e). None of the samples belonging to MSA-C or HS showed PK resistant signals (Fig. 3c,d and Supplementary Fig. 3a).

This difference is probably due to the likelihood that the rec- $\alpha$ Syn substrate was able to acquire distinct abnormal conformations which partially recapitulated those of the original $\alpha \operatorname{Syn}^{\mathrm{D}}$ strains responsible for PD and MSA-P. This may result in important differences in the PK resistance of the $\alpha$ Syn_RT-QuIC reaction products generated from OM samples of PD and MSA-P. Finally, the $\alpha$ Syn $_{-}$ RT-QuIC products obtained from the analysis of MSA-P and MSA-C samples at ITA-lab (collected at $13 \mathrm{~h}$ ) were analyzed by Transmission Electron Microscopy (TEM) and confirmed the presence of amyloid fibrils only in MSA-P samples capable of inducing an efficient seeding activity (except for MSA-P_10 and MSA-P_11 that remained negative by RT-QuIC). The amyloid fibrils were not detected in all MSA-C seeded samples (Supplementary Fig. 4). Similarly, when tested with different fluorescent probes known to bind protein aggregates (dye-binding assay), including ThT, Congo red and amyloidselective marker Amytracker 630 [24], 18 out of 20 MSA-P seeded samples showed a strong fluorescence signal that was instead very weak or absent in all the other MSA tested samples (MSA-P_10, MSAP_11 and all MSA-C) (Supplementary Fig. 5a). Finally, the epitope mapping study performed on Western blot showed the presence of PK resistant rec- $\alpha$ Syn only in MSA-P samples, thus further supporting these findings (Supplementary Fig. 5b). Combined together, these results confirmed that there was a good correlation between the $\alpha$ Syn_RTQuIC seeding activity and the presence of amyloid fibrils in each sample, and that, in contrast to MSA- 
Table 5 Association analyses between aSyn_RT-QulC seeding activity triggered by OM of PD and MSA-P patients and clinical or demographic parameters

\begin{tabular}{|c|c|c|c|}
\hline \multirow[t]{2}{*}{ Clinical/demographic parameter } & \multicolumn{2}{|c|}{ aSyn_RT-QuIC seeding activity } & \multirow[t]{2}{*}{$p$-value ${ }^{*}$} \\
\hline & Positive & Negative & \\
\hline Sex - n (\%) & & & 1 \\
\hline Male & $16(84.21)$ & $3(15.79)$ & \\
\hline Female & $11(78.57)$ & $3(21.43)$ & \\
\hline Cerebellar syndrome - n (\%) & & & 1 \\
\hline Yes & $5(83.33)$ & $1(16.67)$ & \\
\hline No & $22(81.48)$ & $5(18.52)$ & \\
\hline MRI putamen strie - n (\%) & & & 1 \\
\hline Yes & $9(81.82)$ & $2(18.18)$ & \\
\hline No & $18(81.82)$ & $4(18.18)$ & \\
\hline MRI middle cerebellar peduncle $-\mathrm{n}(\%)$ & & & 1 \\
\hline Yes & $4(100)$ & $0(0)$ & \\
\hline No & $23(79.31)$ & $6(20.69)$ & \\
\hline MRI cerebellum - n (\%) & & & 0.58 \\
\hline Yes & $5(71.43)$ & $2(28.57)$ & \\
\hline No & $22(84.62)$ & $4(15.38)$ & \\
\hline Family history of parkinsonisms - n (\%) & & & 1 \\
\hline Yes & $2(66.67)$ & $1(33.33)$ & \\
\hline No & $25(83.33)$ & $5(16.67)$ & \\
\hline Bradykinesia - n (\%) & & & 0.08 \\
\hline Yes & $26(86.67)$ & $4(13.33)$ & \\
\hline No & $1(33.33)$ & $2(66.67)$ & \\
\hline Rigidity - n (\%) & & & 0.01 \\
\hline Yes & $26(89.66)$ & $3(10.24)$ & \\
\hline No & $1(25.00)$ & $3(75.00)$ & \\
\hline Tremor - n (\%) & & & 0.18 \\
\hline Yes & $18(90.00)$ & $2(10.00)$ & \\
\hline No & $9(69.23)$ & $4(30.77)$ & \\
\hline Postural instability - n (\%) & & & 0.02 \\
\hline Yes & $19(95.00)$ & $1(5.00)$ & \\
\hline No & $8(61.54)$ & $5(38.46)$ & \\
\hline Gait freezing - n (\%) & & & 0.14 \\
\hline Yes & $2(50.00)$ & $2(50.00)$ & \\
\hline No & $25(86.21)$ & $4(13.79)$ & \\
\hline RBD - n (\%) & & & 1 \\
\hline Yes & $11(84.62)$ & $2(15.38)$ & \\
\hline No & $16(80.00)$ & $4(20.00)$ & \\
\hline Early gait ataxia (within 3 years of disease onset) $-\mathrm{n}(\%)$ & & & 1 \\
\hline Yes & $1(100.00)$ & $0(0.00)$ & \\
\hline No & $26(81.25)$ & $6(18.75)$ & \\
\hline Gait ataxia - n (\%) & & & 1 \\
\hline Yes & $5(83.33)$ & $1(16.67)$ & \\
\hline No & $22(81.48)$ & $5(18.52)$ & \\
\hline
\end{tabular}


Table 5 Association analyses between aSyn_RT-QulC seeding activity triggered by OM of PD and MSA-P patients and clinical or demographic parameters (Continued)

\begin{tabular}{|c|c|c|c|}
\hline \multirow[t]{2}{*}{ Clinical/demographic parameter } & \multicolumn{2}{|c|}{ aSyn_RT-QuIC seeding activity } & \multirow[t]{2}{*}{$p$-value* } \\
\hline & Positive & Negative & \\
\hline Limb ataxia - n (\%) & & & 0.56 \\
\hline Yes & $5(100.00)$ & $0(0.00)$ & \\
\hline No & $22(78.57)$ & $6(21.43)$ & \\
\hline Cerebellar dysartria - n (\%) & & & 0.56 \\
\hline Yes & $6(100.00)$ & $0(0.00)$ & \\
\hline No & $21(77.78)$ & $6(22.22)$ & \\
\hline Hyposmia - n (\%) & & & 1 \\
\hline Yes & $4(80.00)$ & $1(20.00)$ & \\
\hline No & $23(82.14)$ & $5(17.86)$ & \\
\hline Autonomic failure - n (\%) & & & 0.62 \\
\hline Yes & $21(84.00)$ & $4(16.00)$ & \\
\hline No & $6(75.00)$ & $2(25.00)$ & \\
\hline Orthostatic hypotension - n (\%) & & & 1 \\
\hline Yes & $14(82.35)$ & $3(17.65)$ & \\
\hline No & $13(86.67)$ & $2(13.33)$ & \\
\hline Other cardiovascular dysautonomic symptoms - n (\%) & & & 1 \\
\hline Yes & $20(83.33)$ & $4(16.67)$ & \\
\hline No & $7(77.78)$ & $2(22.22)$ & \\
\hline Urinary disfunction - $\mathrm{n}(\%)$ & & & 0.29 \\
\hline Yes & $23(85.19)$ & $4(14.81)$ & \\
\hline No & $4(66.67)$ & $2(33.33)$ & \\
\hline Other dysautonomia - n (\%) & & & 0.14 \\
\hline Yes & $22(88.00)$ & $3(12.00)$ & \\
\hline No & $5(62.50)$ & $3(37.50)$ & \\
\hline MRI atrophy - n (\%) & & & 1 \\
\hline Yes & $9(81.82)$ & $2(18.18)$ & \\
\hline No & $17(80.95)$ & $4(19.05)$ & \\
\hline Age at brushing - mean (SD) & $61.22(7.88)$ & $61.50(7.82)$ & 0.94 \\
\hline Disease duration at sampling (year) - mean (SD) & $5.37(3.55)$ & $7.83(6.24)$ & 0.19 \\
\hline Beneficial L-DOPA response UPDRS - mean (SD) & $19.52(10.76)$ & $21.67(11.06)$ & 0.66 \\
\hline MDS-UPDRS-III OFF - mean (SD) & $34.48(8.87)$ & $36.33(12.40)$ & 0.67 \\
\hline
\end{tabular}

$S D$ standard deviation

${ }^{*} p$-values from fisher exact test or t-test, as appropriate

$\mathrm{P}$, the MSA-C samples did not efficiently trigger rec- $\alpha$ Syn aggregation.

Therefore, thanks to the combination of these biochemical and morphological analyses, we were able to validate the $\alpha$ Syn_RT-QuIC results, recognize PD and MSA-P, and even discriminate MSA-P from MSA-C.

\section{Discussion}

Accurate diagnoses of PD and MSA early on in their clinical course is challenging because symptoms often overlap [25]. Misdiagnosis negatively impacts the healthcare system and the life of the patients and could lead to erroneous inclusion in clinical trials. Proper diagnosis can be predictive of treatment responsiveness, indeed, in the early stage, MSA-P patients often respond to levodopa while MSA-C patients do not [26]. It is, therefore, necessary to identify the disease phenotype as early as possible, to provide MSA patients with the most appropriate diagnostic and therapeutic care pathways. The same concept is valid for the other $\alpha$ synucleinopathies, including PD, where early and accurate diagnosis allows proper treatment initiation and is 

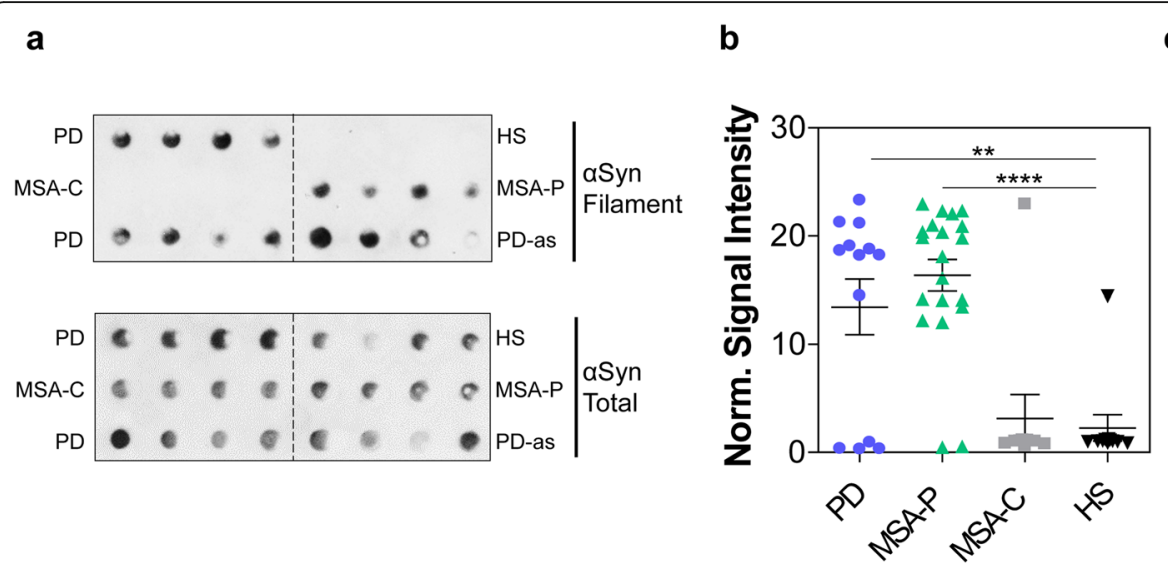

C

Fig. 2 Dot blot immunoassay of aSyn_RT-QulC products from OM-seeded reactions. Representative dot blot images of aSyn_RT-QulC end products from OM samples of patients with PD $(n=2)$, MSA-P $(n=1)$, MSA-C $(n=1)$, and from HS $(n=1)$ obtained using an antibody against aSyn filament or antibody against total aSyn (a). The aSyn_RT-QulC product of an autopsy skin sample from a PD case (PD-as) was used as a positive control [18]. The figure shows that aSyn filament immunoreactivity was present only in the products generated by OM samples of PD and MSA-P but was instead absent in those produced by MSA-C and HS. The total aSyn immunoreactivity was observed in all OM samples. Statistical analysis revealed significantly higher levels of aSyn filament in aSyn_RT-QulC products generated by OM from PD $(p<0.01)$ and MSA-P $(p<0.0001)$ compared to those of MSA-C and HS (one-way ANOVA) (b). Total aSyn levels were comparable between groups $(p=0.0619$, one-way ANOVA) (c). The signal intensity of each dot was normalized to that of HS controls (set to the unit of 1) and represented as mean with SD in (b) and (c). Densitometric analyses in (b) and (c) have been performed on dot blot images of aSyn_RT-QulC products generated from PD ( $n=13$ ), MSA-P $(n=20)$, MSA-C $(n=10)$ and HS $(n=11)$ OM samples at USA-lab (see Supplementary Fig. $3 b)$

key to enrollment into neuroprotective clinical trials. With the development of the seeding aggregation assays (SAAs), including RT-QuIC, significant progress has been made in the field of $\alpha$-synucleinopathy diagnosis. For instance, through RT-QuIC analysis, traces of $\alpha \mathrm{Syn}^{\mathrm{D}}$ were found in the CSF, OM, submandibular gland, and, very recently, skin of diseased patients [12-19]. The identification of $\alpha \operatorname{Syn}^{\mathrm{D}}$ in peripheral tissues may serve as the gold standard for the diagnosis of $\alpha$ synucleinopathies. For this reason, once optimized and integrated into clinical practice, SAAs have the potential to revolutionize the diagnosis, therapy, and prognostication of these diseases.

The majority of the RT-QuIC studies applied to $\alpha$ synucleinopathies were based on CSF samples and highlighted that, besides the impressive performance of the technology in detecting traces of $\alpha \operatorname{Syn}^{\mathrm{D}}$, there are important variabilities in the findings that could be associated with the experimental protocol adopted by each laboratory. The use of customized analytical procedures has hampered the possibility to compare the results and evaluate the reliability and the robustness of the assays. For this reason, we have combined for the first time the expertise of two independent specialized laboratories (ITA-lab and USA-lab) with the aim to explore the interlaboratory reproducibility of RT-QuIC performed on OM samples collected from PD, MSA-C, and MSA-P patients. In contrast to CSF collection that can be painful and associated with adverse effects such as headache or cerebrospinal fluid leak, OM samples can be easily and periodically collected with a minimally invasive procedure. Both of our laboratories harmonized the analytical procedures by minimizing all the experimental variables that could lead to inconsistencies in the results or conflicting findings (e.g. use of a commercially available rec- $\alpha$ Syn). The final $\alpha$ Syn_RT-QuIC protocol that has been developed enabled us to reach a very high IAR (96\%) between ITA-lab and USA-lab. In particular, the OM of $69 \%$ PD patients and 90\% MSA-P patients induced $\alpha$ Syn_RT-QuIC seeding activity with $100 \%$ of IAR. In contrast, none of the OM belonging to MSA-C patients and the HS induced $\alpha$ Syn_RT-QuIC seeding activity at ITA-lab, except for one patient per group at USA-lab, thus leading to 90 and 91\% IAR, respectively. We decided to consider non age-matched HS (younger than the patients) for reducing the probability to include subjects at pre-symptomatic stages of $\alpha$-synucleinopathy, eventually causing positive $\alpha$ Syn_RT-QuIC results difficult to interpret (e.g. real seeding activity vs false positive signal). Surprisingly, OM collected from MSA-P and MSA-C patients showed totally different behavior, with the latter being almost unresponsive to $\alpha$ Syn_RT-QuIC. The lack of seeding activity in MSA-C suggests that, although MSA-P and MSA-C belong to the same disease group, they may be caused by distinct $\alpha \operatorname{Syn}^{\mathrm{D}}$ strains that possess different tropism for peripheral tissues, including the OM. In very recent studies, it has been suggested that $\alpha \operatorname{Syn}^{\mathrm{D}}$ may originate outside the brain, including the nose, the gut and the urogenital tract and then spread to the CNS [27-29]. The tissue 

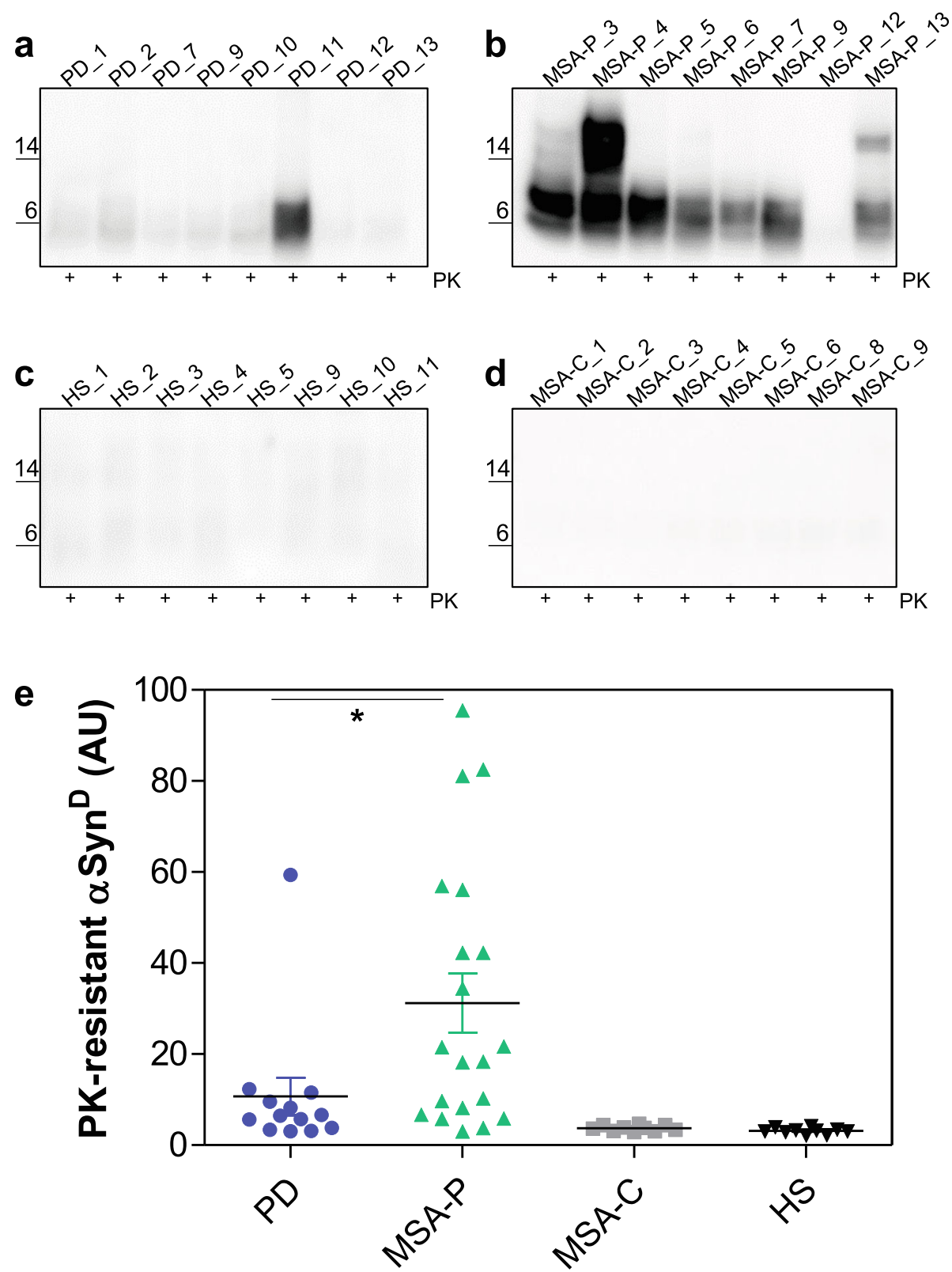

\section{Clinical diagnosis}

Fig. 3 Western blot analyses of aSyn_RT-QulC products from OM-seeded reactions. Representative Western blot images showing the presence of PK resistant bands in aSyn_RT-QulC end products generated by PD $(n=8)(\mathbf{a})$ and MSA-P $(n=8)$ samples $(\mathbf{b})$. Conversely, no bands were detected in aSyn_RT-QulC end products seeded with HS $(n=8)(\mathbf{c})$ and MSA-C $(n=8)(\mathbf{d})$. Statistical analysis revealed that PD generated products were significantly less resistant to PK digestion compared to those generated by MSA-P (Mann-Whitney test $p=0.0104$ ). Densitometric analyses have been performed on Western blot images of aSyn_RT-QulC products generated from PD $(n=13)$, MSA-P $(n=20)$, MSA-C $(n=10)$ and HS $(n=11)$ OM samples at ITA-lab (see Supplementary Fig. 3a). Median with interquartile range is shown (e)

microenvironment might influence $\alpha \operatorname{Syn}^{\mathrm{D}}$ properties thus driving its tropism for specific neuroanatomical regions. This might lead to the onset of different forms of MSA and contribute to the phenotypic heterogeneity of $\alpha$-synucleinopathies.

Interesting findings indicate that even different $\alpha$ Syn strains can be found within the same MSA brain [30].
Since the brain homogenates of MSA-C patients were able to induce an efficient $\alpha$ Syn_RT-QuIC seeding activity using our protocol, we speculate that the $\alpha \operatorname{Syn}^{\mathrm{D}}$ strain responsible for MSA-C (i) might not be present in the OM (while that associated with MSA-P accumulates in this tissue with greater efficiency), (ii) might be present in the OM but could be subjected to tissue/ 
microenvironment specific changes that make this strain incapable of triggering the seeding activity, or (iii) might be present in the OM but at concentrations which are still too low to induce a detectable seeding activity. Regardless of the reasons which determine this opposite $\alpha$ Syn_RT-QuIC behavior of MSA-P and MSA-C, the findings can be exploited to efficiently distinguish these different pathologies in living patients. Several research groups have subjected to RT-QuIC analysis the CSF of patients with MSA but controversial results were reported [15, 31-34]. Moreover, except for a few papers, there were no clear indications about the subtypes of MSA examined and whether specific correlations between the disease phenotype and the RT-QuIC outcomes were observed. Interestingly, van Rumund and colleagues reported that only a small group of CSF samples belonging to MSA-P patients were able to induce seeding activity by RT-QuIC, while those belonging to MSA-C patients did not [33]. Although these data refer to a different biological sample, they are in line with those of our OM study and further support the hypothesis that MSA-P and MSA-C may be caused by distinct $\alpha \operatorname{Syn}^{\mathrm{D}}$ strains with peculiar tropism for CSF, OM, and likely other peripheral tissues. Our findings might also unveil different biological and molecular pathways involved in the disease pathogenesis.

Notably, in PD and MSA-P patients we found a positive significant association between $\alpha$ Syn_RT-QuIC seeding activity and some clinical parameters, including rigidity and postural instability. In contrast, we did not find any correlation between $\alpha$ Syn_RT-QuIC seeding activity and the disease duration.

Taken together, these data indicate that through a careful combination of aggregation kinetics, biochemical and morphological assays, and clinical information, the $\alpha$ Syn_RT-QuIC assay of OM can significantly improve the clinical diagnosis of $\alpha$-synucleinopathies. In particular, the assay may help physicians to identify and stratify patients with PD and MSA and, above all, to specifically recognize MSA-P or MSA-C phenotypes.

The high degree of interlaboratory reproducibility strongly supports the reliability and the robustness of the $\alpha$ Syn_RT-QuIC results. Therefore, the fact that some $\mathrm{OM}$ of PD patients and almost all OM of MSA-C patients did not induce $\alpha$ Syn_RT-QuIC seeding activity does not represent a technical limitation of the assay (e.g. lack of sensitivity). These findings could also not be the result of stochastic events. We rather think that there might be additional significant biological and pathophysiological reasons that cannot be totally understood at present. Certainly, we can benefit from betterrecognizing patients with $\mathrm{PD}, \mathrm{MSA}-\mathrm{P}$, and MSA-C, and potentially identifying heterogeneous pathological subgroups within these diagnoses, in order to pave the way to tailored treatment regimens.

For all these reasons, OM-based $\alpha$ Syn_RT-QuIC analysis may be a promising candidate as a routine diagnostic test for PD, MSA-P, and MSA-C. Additionally, this assay requires further studies to determine whether it will identify presymptomatic and prodromal PD and MSA patients. If this were the case, $\alpha$ Syn_RT-QuIC could be helpful to identify subjects at risk of developing the disease, and can be particularly important in this very moment where preliminary studies suggest that the Sars-CoV-2 viral infection seems to influence the vulnerability to PD [35]. Finally, the assay can be exploited to test in vitro the efficacy of therapeutic compounds to interfere with the aggregation of $\alpha$ Syn in reactions seeded with patients' biological samples.

The fact that few, if any, of the patients included in our work will undergo neuropathological assessment, represents the major limitation of the study that cannot be addressed. The lack of OM samples collected from pathologically confirmed cases of PD, MSA-C, and MSA-P hampers the possibility to perform a retrospective analysis for estimating the sensitivity and specificity of the assay. Moreover, the quantity of OM sample collectible from each patient is considerably limited. For this reason, we have decided to perform this preliminary work of protocol set-up and harmonization by involving no more than two specialized laboratories with the aim of having enough material to be accurately and repeatedly analyzed by both groups. As a matter of fact, almost the entire volume of each OM sample included in this work was consumed during the analyses before reaching the conclusion that the samples can be significantly diluted (up to 20X) without affecting the sensitivity and specificity of the $\alpha$ Syn_RT-QuIC. This observation should be taken into account for future studies, where newly collected OM can be prepared as described and used to perform multicenter studies for a better assessment of the $\alpha$ Syn_RT-QuIC performances. The limited number of samples included in this study depends on the fact that MSA is a rare disease and that the COVID19 pandemic outbreak has imposed severe limitations on OM collection for biosafety reasons. Nevertheless, our exploratory study showed striking differences in $\alpha S_{y}$ RT-QuIC responses between (1) MSA-C and MSA-P, (2) MSA-C and PD, (3) MSA-P and controls, and (4) PD and controls that were faithfully reproducible in both laboratories thus demonstrating that they were not due to merely stochastic events. Although the analytical procedures have been harmonized, two different thresholds of time were set at ITA-lab and USA-lab to discriminate positive and negative samples. Likely, despite using the same instrument (BMG LabTech OMEGA), some conditions may inevitably differ (e.g. the stability of the 
temperature during the whole analytical process or the mechanism of shaking of the plate) hence promoting the variability in the time thresholds between labs. In addition, other factors, including the precision of the pipettes or the type of consumables (e.g. tubes) used for the analysis might have favored this discrepancy. Certainly, additional studies would help to define a window of time, instead of a single lab-dependent timethreshold, within which the samples can be considered positive.

Longitudinal studies using samples collected from larger cohorts of patients are required to definitively evaluate the diagnostic accuracy of OM- $\alpha \operatorname{Syn}^{\mathrm{D}}$ as a biomarker for PD, MSA-P, MSA-C, and other $\alpha$-synucleinopathies. However, we believe that these evaluations should be performed at the end of the COVID-19 pandemic since, at present, we do not know whether the potential presence of the Sars-CoV-2 virus in the nasal cavity of either diseased patients or healthy subjects might alter the properties of the OM samples while compromising the $\alpha$ Syn_RT-QuIC analyses.

Finally, additional investigations will also be needed to determine whether this assay could be used as a biomarker to track disease progression and monitor the effect of disease-modifying treatments.

\section{Conclusions}

The use of the ultrasensitive RT-QuIC assay could potentially help the field of $\alpha$-synucleinopathy diagnosis, but a process of assay harmonization is urgently needed to minimize the variability or conflicting findings between specialized laboratories. Our results suggest that PD, MSA-P, and MSA-C are caused by distinct $\alpha \operatorname{Syn}^{\mathrm{D}}$ strains that might have peculiar pathological features and tropism for peripheral tissues, including OM, eventually unveiling different biological and molecular pathways involved in the disease pathogenesis. This study provides evidence that $\alpha$ Syn_RT-QuIC of OM samples represents a reliable assay that can distinguish patients with MSA-P from those with MSA-C, and may limit the negative effects that misdiagnosis produces in terms of costs for the healthcare system and improve overall patient care, treatment, and possible enrollment in future clinical trials.

\footnotetext{
Abbreviations

aSyn: a-synuclein; MSA: Multiple system atrophy; PD: Parkinson's disease; OM: Olfactory mucosa; aSyn_RT-QulC: a-synuclein Real-Time QuakingInduced Conversion; MSA-P: Multiple system atrophy with the parkinsonian phenotype; MSA-C: Multiple system atrophy with the cerebellar phenotype; HS: Healthy control subjects; IAR: Interrater agreement of results; MRI: Magnetic resonance imaging; RT-QulC: Real-Time Quaking-Induced Conversion; CSF: Cerebrospinal fluid; MDS-UPDRS: Movement Disorder SocietyUnified Parkinson's Disease Rating Scale; I-123 MIBG: lodine 123 ( ${ }^{123}$ |) metaiodobenzylguanidine; SPET-DATSCAN: Single Photon Emission Tomography - Dopamine Transporter Scan; FDG-PET: ${ }^{18}$ F-fluorodeoxyglucose Positron Emission Tomography; RBD: Rapid eye movement sleep Behavior
}

Disorder; L-DOPA: Levodopa; PBS: Phosphate-buffer saline; recaSyn: Recombinant human a-synuclein; ThT: Thioflavin-T; AU: Arbitrary units; SD: Standard deviation; SEM: Standard error of the mean; BSA: Bovine serum albumin; TBST: Tris-Buffered Saline containing Tween-20; PK: Proteinase K; PVDF: Polyvinylidene difluoride; BH: Brain homogenate; TEM: Transmission Electron Microscopy; SAA: Seeding aggregation assay; COVID-19: COronaVlrus Disease 19; Sars-CoV-2: Severe Acute Respiratory Syndrome Coronavirus-2

\section{Supplementary Information}

The online version contains supplementary material available at https://doi. org/10.1186/s13024-021-00491-y.

Additional file 1. Detection of aSyn_RT-QulC seeding activity triggered by the brain homogenates of patients with PD, MSA-P, and MSA-C. We tested the performance of the new aSyn RT-QuIC protocol using the brain homogenates $(\mathrm{BH})$ of autopsy-confirmed cases of PD $(n=1)$, MSA-P $(n=1)$, and MSA-C $(n=1)$ as sources of different $a S_{y n}{ }^{D}$ strains. The $\mathrm{BH}$ of a patient not affected by a-synucleinopathy (NAS) was used as control. Immunohistochemical analysis revealed the presence of distinct aSyn ${ }^{D}$ aggregates in the brain of tested patients, except for NAS. MSA-P and NAS images were taken using 10x magnification. MSA-C and PD images were taken using 40x magnification (a). Frozen brain samples (substantia nigra for PD, striatum for MSA-P, cerebellum for MSA-C, and frontal cortex for NAS) were homogenized at 10\% in PBS (weight/volume) and diluted at $10^{-12}$. One $\mu$ l of each $\mathrm{BH}$ was added to $49 \mu \mathrm{L}$ of reaction mix and subjected to aSyn_RT-QulC analysis. The results indicate that PD (light green line), MSA-P (blue line), and MSA-C (grey line) induced aSyn_RT-QulC seeding activity before the time threshold set at $13 \mathrm{~h}$ while that of the patient with NAS (purple line) did not (b). Each sample was analyzed in quadruplicate. Curves represented in the graph were obtained by plotting the average fluorescence intensities of each sample against time.

Additional file 2. Time to threshold and mean fluorescence at time threshold obtained at ITA-lab and USA-lab. At ITA-lab, time to threshold was significantly shorter in reactions seeded with OM samples of PD compared to that of MSA-P (unpaired t-test, $p=0.017$ ) (a) while at USAlab they were comparable (unpaired t-test, $p=0.3944)(b)$. No significant differences in the average of fluorescence values reached by PD and MSA samples at the time threshold were observed in both ITA-lab $(146,494 \pm 103,670 \mathrm{AU}$ (mean \pm SD) and 147,298 \pm 80,123 AU, respectively; Mann-Whitney test, $p=0.9853$ ) (c) and USA-lab (108,961 $\pm 110,426 \mathrm{AU}$ and 119,929 $\pm 83,655 \mathrm{AU}$, respectively; Mann-Whitney test, $p=0.4279$ ) (d). In $\mathrm{a}$ and $\mathrm{b}$, means with $95 \% \mathrm{Cl}$ are shown. In $\mathrm{c}$ and $\mathrm{d}$, medians with interquartile range are shown.

Additional file 3. Biochemical analysis of aSyn_RT-QulC reaction products. Western blot images of aSyn_RT-QulC reaction products obtained at ITA-lab from OM samples of all individuals (PD $=13$, MSA-P = 20 , MSA-C $=10$ and $H S=11$ ) that were used for quantification analysis reported in Fig. 3e. Samples were digested with PK $(2.5 \mathrm{mg} / \mathrm{mL})$ and immunoblotted with the rabbit polyclonal a-synuclein antibody Agrisera AS08 358 (1:1,000). PK resistant bands were observed in several aSyn_RT-QulC end products seeded with PD and MSA-P samples while they were not detected in all MSA-C and HS seeded samples. Vertical dashed lines in each blot indicate cropped images from separate gels (a). Dot blot images of aSyn_RT-QuIC reaction products obtained at USA-lab from OM samples of all individuals ( $P D=13, M S A-P=20, M S A-C=10$ and $H S=11$ ) that were used for quantification analysis reported in Fig. $2 \mathrm{~b}$ and $\mathrm{c}$. Total aSyn signal from these products was present in all samples while aSyn filament signal was present only in samples which induced aSyn_RT-QulC seeding activity (b).

Additional file 4. Morphological analsysis of aSyn_RT-QulC reaction products generated by MSA-P and MSA-C samples at ITA-lab. aSyn_RTQuIC reaction products were properly diluted and $10 \mu \mathrm{L}$ of the final dilutions was dropped onto 200-mesh Formvar-carbon coated nickel grids for $30 \mathrm{~min}$ and the remaining drop was blotted dry using filter papers. Samples were stained with 25\% Uranyl Acetate Replacement (UAR, negative staining) for $10 \mathrm{~min}$, the solution was removed using filter papers and the grids were air-dried for 15 min before the analyses. Images were recorded at $120 \mathrm{kV}$ with a FEl Tecnai Spirit, equipped with an Olimpus 
Megaview G2 camera. Rec-aSyn amyloid fibrils were detected in all aSyn_RT-QulC products seeded with MSA-P samples, except for MSAP_10 and MSA-P_11. In constrast, none of the MSA-C samples induced the formation of rec-aSyn fibrils (except for occasional, rare and short aggregates detected in MSA-C_1, MSA-C_3 and MSA-C_6). All TEM images were taken at the same magnification (scale bar: $200 \mathrm{~nm}$ ).

Additional file 5. Dye-binding assay and epitope mapping of aSyn_RTQulC products generated by MSA-P $(n=20)$ and MSA-C $(n=10)$ samples at ITA-lab. Thirty-five $\mu \mathrm{L}$ of aSyn_RT-QulC products, generated without the use of ThT, were incubated with three different fluorescent dyes: (i)

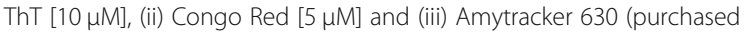
from Ebba Biotech and diluted 1:800) for $30 \mathrm{~min}$ in the dark at room temperature. Fluorescent signals were measured with the appropriate wave-lengths (448 exc/482 emi for ThT, 544 exc/620 emi for Congo red and 510 exc/635 emi for Amytracker 630) using the BMG LabTech CLARIOSTAR microplate reader. Regardless of the probe used, all MSA-P samples (except for MSA-P_10 and MSA-P_11) showed strong fluorescent signals while the MSA-C did not. These differences were statistically significant in the case of (i) ThT ( $t$-test $p=0.0063$ ), (ii) Congo red ( $t$-test, $p=$ 0.0018 ) and (iii) Amytracker 630 (t-test, $p=0.0051$ ). Graphs show the mean values ( \pm SEM) of MSA-P and MSA-C fluorescent signals obtained from (i) ThT (graph on the left), (ii) Congo red (graph in the middle) and (iii) Amytracker 630 (graph on the right) analysis (a). Eight $\mu \mathrm{L}$ of aSyn_RTQulC products generated by MSA-P and MSA-C samples were treated with PK $[2.5 \mathrm{mg} / \mathrm{mL}]$ for $1 \mathrm{~h}$ at $37^{\circ} \mathrm{C}$ under shaking (500 rpm) and immunoblotted with antibodies directed against three different epitopes of asynuclein: (i) clone 5C2 (epitopes 61-95, Novus Biologicals), (ii) AB5038 (epitopes 111-131, Chemicon international), and (iii) clone 42 (epitopes 15-123, BD Bioscience). No signals were observed in samples immunoblotted with the AB5038 and the clone 5C2, while with the clone 42, PK resistant bands were specifically detected in aSyn_RT-QulC products seeded with MSA-P but not in those seeded with MSA-C samples (b).

\section{Acknowledgements}

Not applicable.

\section{Authors' contributions}

FM and SGC designed and supervised the study. FM and FAC submitted the ethics application. GD, AEE, RC, and RE selected and characterized patients for OM collection. SMP performed brushing procedures. AD and GG selected and provided brain homogenates for RT-QulC analysis. CB performed RTQulC and dot blot analyses. CMGD processed OM samples and performed RT-QulC and Western blot analyses. WW provided technical assistance during the study. EB and FAC performed part of OM processing and RT-QulC analysis. IT performed statistical analysis. FM, SGC, CB, CMGD, GD, and IT analyzed the data. FM and SGC drafted the manuscript. CMGD and GD prepared tables and Figs. GD, IT, GF, GL, AD, RX, SAG, and GG interpreted the data. All authors read, reviewed, and approved the manuscript.

\section{Funding}

FM was supported in part by the Italian Ministry of Health (GR-201302355724 and Current Research), the Michael J. Fox Foundation, Alzheimer's Association, Alzheimer's Research UK and the Weston brain Institute (BAND 11035) and Associazione Italiana Encefalopatie da Prioni (AIEnP). SGC was supported in part by the American Parkinson Disease Association, the US National Institutes of Health ( $\mathrm{NIH}) /$ National Institute on Aging (R01AG061388), and NIH/National Institute of Neurological Disorders and Stroke (U01NS112010 and R01NS118760).

\section{Availability of data and materials}

All data generate or analysed during this study are included in this published article (and its supplementary information files).

\section{Declarations}

\section{Ethics approval and consent to participate}

All the procedures involving human participants were performed in accordance with the ethical standards of the institutional and/or national research committees and with the 1964 Helsinki declaration. The study and its ethical aspects were approved by the Fondazione IRCCS Istituto
Neurologico Carlo Besta ethical committee. All of the participants provided written informed consent before OM collection and analysis.

\section{Consent for publication}

Not applicable.

\section{Competing interests}

The authors declare that they have no competing interests.

\section{Author details}

${ }^{1}$ Department of Pathology, Case Western Reserve University School of Medicine, Cleveland, OH, USA. ${ }^{2}$ Unit of Neurology 5 and Neuropathology, Fondazione IRCCS Istituto Neurologico Carlo Besta, Milan, Italy. ${ }^{3}$ Department of Neuroscience, Scuola Internazionale Superiore di Studi Avanzati (SISSA), Trieste, Italy. ${ }^{4}$ Unit of Neurology 1 - Parkinson and Movement Disorders, Fondazione IRCCS Istituto Neurologico Carlo Besta, Milan, Italy. ${ }^{5}$ Department of Health Science, Santi Paolo e Carlo Hospital and Università degli Studi di Milano, Milan, Italy. ${ }^{6}$ Scientific Directorate, Fondazione IRCCS Istituto Neurologico Carlo Besta, Milan, Italy. 'Unit of Neurology, Foundation IRCCS $\mathrm{Ca}^{\prime}$ Granda Ospedale Maggiore, Milan, Italy. ${ }^{8}$ Department of Population and Quantitative Health Sciences, Case Western Reserve University School of Medicine, Cleveland, OH, USA. ${ }^{9}$ Department of Neurology, Case Western Reserve University School of Medicine, Cleveland, OH, USA. ${ }^{10}$ Department of Neurology, University Hospitals Cleveland Medical Center, Cleveland, $\mathrm{OH}$, USA.

Received: 3 May 2021 Accepted: 13 September 2021 Published online: 11 December 2021

\section{References}

1. Gilman S, Wenning GK, Low PA, Brooks DJ, Mathias CJ, Trojanowski JQ, et al. Second consensus statement on the diagnosis of multiple system atrophy. Neurology. 2008;71(9):670-6. https://doi.org/10.1212/01.wnl.0000324625.004 04.15 .

2. Lee H-J, Ricarte D, Ortiz D, Lee S-J. Models of multiple system atrophy. Exp Mol Med. 2019;51 (11):1-10. https://doi.org/10.1038/s12276-019-0350-z.

3. Valera $E$, Masliah $E$. The neuropathology of multiple system atrophy and its therapeutic implications. Auton Neurosci. 2018;211:1-6. https://doi.org/10.1 016/j.autneu.2017.11.002.

4. Koga S, Dickson DW. Recent advances in neuropathology, biomarkers and therapeutic approach of multiple system atrophy. J Neurol Neurosurg Psychiatry. 2018;89(2):175-84. https://doi.org/10.1136/jnnp-2017-315813.

5. Doty RL. Olfactory dysfunction in Parkinson disease. Nat Rev Neurol. 2012; 8(6):329-39. https://doi.org/10.1038/nrneurol.2012.80

6. Glass PG, Lees AJ, Mathias C, Mason L, Best C, Williams DR, et al. Olfaction in pathologically proven patients with multiple system atrophy. Mov Disord. 2012;27(2):327-8. https://doi.org/10.1002/mds.23972.

7. Palma JA, Norcliffe-Kaufmann L, Kaufmann H. Diagnosis of multiple system atrophy. Auton Neurosci. 2018;211:15-25. https://doi.org/10.1016/j.autneu.2 017.10.007.

8. Spillantini MG, Goedert M. Synucleinopathies: past, present and future. Neuropathol Appl Neurobiol. 2016;42(1):3-5. https://doi.org/10.1111/na n.12311.

9. Trojanowski JQ, Revesz T. Neuropathology working group on MSA. Proposed neuropathological criteria for the post mortem diagnosis of multiple system atrophy. Neuropathol Appl Neurobiol. 2007;33(6):615-20. https://doi.org/10.1111/j.1365-2990.2007.00907.x.

10. Yamasaki TR, Holmes BB, Furman JL, Dhavale DD, Su BW, Song E-S, et al. Parkinson's disease and multiple system atrophy have distinct a-synuclein seed characteristics. J Biol Chem. 2019;294(3):1045-58. https://doi.org/10.1 074/jbc.RA118.004471.

11. Miki Y, Foti SC, Asi YT, Tsushima E, Quinn N, Ling H, et al. Improving diagnostic accuracy of multiple system atrophy: a clinicopathological study. Brain. 2019;142(9):2813-27. https://doi.org/10.1093/brain/awz189.

12. Fairfoul G, McGuire LI, Pal S, Ironside JW, Neumann J, Christie S, et al. Alphasynuclein RT-QulC in the CSF of patients with alpha-synucleinopathies. Ann Clin Transl Neurol. 2016;3(10):812-8. https://doi.org/10.1002/acn3.338.

13. Groveman BR, Orrù CD, Hughson AG, Raymond LD, Zanusso G, Ghetti B, et al. Rapid and ultra-sensitive quantitation of disease-associated a-synuclein seeds in brain and cerebrospinal fluid by aSyn RT-QulC. Acta Neuropathol Commun. 2018;6(1):7. https://doi.org/10.1186/s40478-018-0508-2. 
14. Manne S, Kondru N, Hepker M, Jin H, Anantharam V, Lewis M, et al. Ultrasensitive detection of aggregated a-Synuclein in glial cells, human cerebrospinal fluid, and brain tissue using the RT-QulC assay: new highthroughput Neuroimmune biomarker assay for Parkinsonian disorders. $J$ Neurolmmune Pharmacol. 2019;14(3):423-35. https://doi.org/10.1007/s114 81-019-09835-4.

15. Shahnawaz M, Tokuda T, Waragai M, Mendez N, Ishii R, Trenkwalder C, et al. Development of a biochemical diagnosis of Parkinson disease by detection of a-Synuclein Misfolded aggregates in cerebrospinal fluid. JAMA Neurol. 2017;74(2):163-72. https://doi.org/10.1001/jamaneurol.2016.4547.

16. De Luca CMG, Elia AE, Portaleone SM, Cazzaniga FA, Rossi M, Bistaffa E, et al. Efficient RT-QulC seeding activity for a-synuclein in olfactory mucosa samples of patients with Parkinson's disease and multiple system atrophy. Transl Neurodegener. 2019;8(1):24. https://doi.org/10.11 86/s40035-019-0164-x.

17. Manne S, Kondru N, Jin H, Serrano GE, Anantharam V, Kanthasamy A, et al. Blinded RT-QulC analysis of a-Synuclein biomarker in skin tissue from Parkinson's disease patients. Mov Disord. 2020;35(12):2230-9. https://doi. org/10.1002/mds.28242.

18. Wang Z, Becker K, Donadio V, Siedlak S, Yuan J, Rezaee M, et al. Skin aSynuclein aggregation seeding activity as a novel biomarker for Parkinson disease. JAMA Neurol. 2020;78(1):1-11.

19. Perra D, Bongianni M, Novi G, Janes F, Bessi V, Capaldi S, et al. Alphasynuclein seeds in olfactory mucosa and cerebrospinal fluid of patients with dementia with Lewy bodies. Brain Commun. 2021;3(2). https://doi.org/10.1 093/braincomms/fcab045.

20. Kang UJ, Boehme AK, Fairfoul G, Shahnawaz M, Ma TC, Hutten SJ, et al. Comparative study of cerebrospinal fluid a-synuclein seeding aggregation assays for diagnosis of Parkinson's disease. Mov Disord. 2019;34(4):536-44. https://doi.org/10.1002/mds.27646.

21. Postuma RB, Berg D, Stern M, Poewe W, Olanow CW, Oertel W, et al. MDS clinical diagnostic criteria for Parkinson's disease. Mov Disord. 2015;30(12): 1591-601. https://doi.org/10.1002/mds.26424.

22. Goetz CG, Tilley BC, Shaftman SR, Stebbins GT, Fahn S, Martinez-Martin P, et al. Movement Disorder Society-sponsored revision of the unified Parkinson's disease rating scale (MDS-UPDRS): scale presentation and clinimetric testing results. Mov Disord. 2008;23(15):2129-70. https://doi.org/1 $0.1002 /$ mds. 22340 .

23. Metrick MA, do Carmo Ferreira N, Saijo E, Hughson AG, Kraus A, Orrú C, et al. Million-fold sensitivity enhancement in proteopathic seed amplification assays for biospecimens by Hofmeister ion comparisons. Proc Natl Acad Sci. 2019;1 16(46):23029-39. https://doi.org/10.1073/pnas.1 909322116.

24. de Waal GM, de Villiers WJS, Forgan T, Roberts T, Pretorius E. Colorectal cancer is associated with increased circulating lipopolysaccharide, inflammation and hypercoagulability. Sci Rep. 2020;10(1):8777. https://doi. org/10.1038/s41598-020-65324-2

25. Hughes AJ, Daniel SE, Ben-Shlomo Y, Lees AJ. The accuracy of diagnosis of parkinsonian syndromes in a specialist movement disorder service. Brain. 2002;125(Pt 4):861-70. https://doi.org/10.1093/brain/awf080.

26. Wenning GK, Geser F, Krismer F, Seppi K, Duerr S, Boesch S, et al. The natural history of multiple system atrophy: a prospective European cohort study. Lancet Neurol. 2013;12(3):264-74. https://doi.org/10.1016/S1474-4422 (12)70327-7

27. Hawkes CH, Del Tredici K, Braak H. Parkinson's disease: a dual-hit hypothesis. Neuropathol Appl Neurobiol. 2007;33(6):599-614. https://doi.org/10.1111/ j.1365-2990.2007.00874.x.

28. Hawkes CH, Del Tredici K, Braak H. Parkinson's disease. Ann N Y Acad Sci. 2009;1170(1):615-22. https://doi.org/10.1111/j.1749-6632.2009.04365.X.

29. Ding $X$, Zhou L, Jiang $X$, Liu $H$, Yao J, Zhang $R$, et al. Propagation of Pathological a-Synuclein from the Urogenital Tract to the Brain Initiates MSA-like Syndrome. iscience. 2020;23(6):101166.

30. Schweighauser M, Shi Y, Tarutani A, Kametani F, Murzin AG, Ghetti B, et al. Structures of a-synuclein filaments from multiple system atrophy. Nature. 2020;585(7825):464-9. https://doi.org/10.1038/s41586-020-2317-6.

31. Rossi M, Candelise N, Baiardi S, Capellari S, Giannini G, Orrù CD, et al. Ultrasensitive RT-QulC assay with high sensitivity and specificity for Lewy body-associated synucleinopathies. Acta Neuropathol. 2020;140(1):49-62. https://doi.org/10.1007/s00401-020-02160-8.

32. Shahnawaz M, Mukherjee A, Pritzkow S, Mendez N, Rabadia P, Liu X, et al. Discriminating a-synuclein strains in Parkinson's disease and multiple system atrophy. Nature. 2020;578(7794):273-7. https://doi.org/10.1038/s41 586-020-1984-7.

33. van Rumund A, Green AJE, Fairfoul G, Esselink RAJ, Bloem BR, Verbeek MM. a-Synuclein real-time quaking-induced conversion in the cerebrospinal fluid of uncertain cases of parkinsonism. Ann Neurol. 2019;85(5):777-81. https:// doi.org/10.1002/ana.25447.

34. Bongianni M, Ladogana A, Capaldi S, Klotz S, Baiardi S, Cagnin A, et al. aSynuclein RT-QuIC assay in cerebrospinal fluid of patients with dementia with Lewy bodies. Ann Clin Transl Neurol. 2019;6(10):2120-6. https://doi. org/10.1002/acn3.50897.

35. Pavel A, Murray DK, StoessI AJ. COVID-19 and selective vulnerability to Parkinson's disease. Lancet Neurol. 2020;19(9):719. https://doi.org/10.1016/ S1474-4422(20)30269-6.

\section{Publisher's Note}

Springer Nature remains neutral with regard to jurisdictional claims in published maps and institutional affiliations.
Ready to submit your research? Choose BMC and benefit from:

- fast, convenient online submission

- thorough peer review by experienced researchers in your field

- rapid publication on acceptance

- support for research data, including large and complex data types

- gold Open Access which fosters wider collaboration and increased citations

- maximum visibility for your research: over $100 \mathrm{M}$ website views per year

At BMC, research is always in progress.

Learn more biomedcentral.com/submissions 